\title{
1. Kapitel
}

\section{Die sozialdemokratische Tradition des Elternhauses}

Mein Vater Friedrich August Geyer, ${ }^{1}$ ein alter Freund und Mitarbeiter August Bebels, ${ }^{2}$ seit dem Jahr 1890 sozialdemokratischer Reichstagsabgeordneter für den Wahlkreis Leipzig-Land, hatte den Ehrgeiz, seinen beiden Söhnen die beste damals mögliche Schulerziehung und Bildung angedeihen zu lassen. Er brachte für diesen Zweck beträchtliche finanzielle Opfer. In seiner Haltung wurde er bestärkt, als die beiden Söhne schon in ihren ersten Schuljahren überdurchschnittliche Intelligenz bewiesen. Der Satz „Wissen ist Macht“ gehörte in den Anfängen der deutschen Arbeiterbewegung zu den Hauptlehren, die den Arbeitern von ihren Führern eingeprägt wurden, und mein Vater hielt sich daran. Diese Vorstellungen entsprachen dem Bildungsstreben des deutschen Bürgertums von damals. Ich habe diesen Satz immer wieder in meinem Elternhaus gehört und in der populären sozialdemokratischen Propagandaliteratur der Frühzeit gelesen.

Mein Vater stammte aus kleinen Anfängen, aus einer sächsischen Kleinbürgerfamilie. Er war Zigarrenmacher und erlebte in seiner Jugend noch die Zeit, in der diese Arbeiterkategorie zur Elite der gelernten Arbeiter gehörte - was nicht nur in ihrem Verdienst, sondern auch in ihrem Standesgefühl und ihrem Gebaren zum Ausdruck kam. In dem kleinen Städtchen Großenhain pflegte er sonntags mit seinen Kollegen in Frack und Zylinderhut auf der Promenade spazieren zu gehen. Dabei gewann er die Hand meiner Mutter, einer Großenhainer Bürgerstochter, die nach den damaligen Anschauungen sozial über ihm stand. Mit dem höheren Status der Mutter war es übrigens nicht weit her. Ihr Vater war Spinnmeister in einer Baumwollspinnerei, ihre Mutter kam aus einer Bauernfamilie in dem Dorf Lenz bei Großenhain. Die Familie besaß ein eigenes Haus an der Promenade. Trotzdem ging es knapp zu. Meine Mutter wurde zunächst als Kochlehrling zur Köchin eines Großenhainer Geistlichen geschickt, deren Stelle sie später selber übernahm. Der Zigarrenmacher, der mit schmetternder Stimme rührende Lieder singen konnte, war wegen seiner politischen Neigungen bei den Bürgern als "Roter" in Verruf. Auf Grund seines fleißigen Selbststudiums hielt er sich schon damals für einen der Führer in der aufkeimenden Arbeiterbewegung. Als er sich mit der Köchin des Archidiakonus von Großenhain verehelichte, war der Skandal groß und der Zigarrenmacher Geyer fand in Großenhain keine Arbeitsstelle mehr. Mit einer kleinen Mitgift meiner Mutter und dem Gelde eines Kompagnons gründete er eine kleine Zigarrenfabrik in dem Städtchen. Die Zigarrenfabrik Friedrich Geyer \& Co. beschäftigte selbst in ihren besten Zeiten nie mehr als ein Dutzend Arbeiter und Arbeiterinnen. Das Einkommen des Fabrikanten hielt die Familie nur notdürftig über Wasser. Die Familie übersiedelte nach Leipzig, wo dem Vater eine Redakteurstelle am „Volksstaat", einem Vorläufer der Leipziger Volkszeitung, angeboten worden war. Dieser

1 Friedrich Geyer (1853-1937), 1885-1897 Mitglied der zweiten Kammer des Sächs. Landtags, 1886-1887 und 1890-1924 MdR, 1918/19 sächs. Finanzminister.

2 August Bebel (1840-1913), Drechsler, ab 1867 Vors. d. Verbands deutscher Arbeitervereine, 1866 Mitgründer der Sächs. Volkspartei, 1869 Mitgründer der sozialdemokratischen Arbeiterpartei, seit 1880 Vorstandsmitglied, 1892-1913 Vorsitzender der SPD. 
Posten wurde sehr dürftig bezahlt, aber das Einkommen ergänzte die Einkünfte aus der Zigarrenfabrik. Mein Vater besaß die Freundschaft und das Wohlwollen August Bebels und wurde bald zur Seele der Leipziger Arbeiterbewegung. Später fand er eine andere journalistische Beschäftigung als Redakteur der Gewerkschaftszeitung „Der Tabakarbeiter", die in der Druckerei der „Leipziger Volkszeitung“ hergestellt wurde. Diese Anstellung behielt er bis kurz vor seiner Pensionierung. In dieser Gewerkschaftszeitung verdiente ich mir in sehr frühen Jahren meine journalistischen Sporen. Der Vater hielt den Status des Zigarrenfabrikanten trotz seiner vorwiegend journalistischen Tätigkeit aufrecht und in den Parlamentsferien reiste der Herr Reichstagsabgeordnete bei Konsumvereinen umher, um seine gar nicht üblen Zigarren abzusetzen, deren Qualität ich schon im zarten Alter von vier Jahren ausprobiert hatte - mit katastrophalen Folgen.

Im Jahre 1890, nach dem Fall des Sozialistengesetzes, eroberte der Vater den Wahlkreis Leipzig-Land für die Sozialdemokratische Partei. Er hat ihn bis zum Jahre 1924. mit stets steigenden Mehrheiten vertreten. Vor dem Jahre 1890 vertrat er einen sächsischen Industriewahlkreis im Landtag. Der Wahlkreis Leipzig-Stadt als Zentrum der Universitäts- und Handelsstadt dagegen blieb mit geringer Unterbrechung in der Hand der Nationalliberalen. Der Abgeordnete für Leipzig-Land war somit der einzige Vertreter der gesamten Organisation der Sozialdemokratischen Partei Leipzigs im Reichstag. Seine Autorität in der Partei war unbestritten, aber auch darüber hinaus genoß er großes Ansehen. [...]

Das Parlament hielt den Vater an fünf Tagen in der Woche in Berlin fest, wo er ein möbliertes Zimmer gemietet hatte. Die Folge davon war, daß mein älterer Bruder und ich uns selbst erzogen. Dabei stand die ziemlich reichhaltige Bibliothek des Vaters zu unserer vollen Verfügung. Wenn jemand da gewesen wäre, um mich zu erziehen, so hätte ich vermutlich für ein schwer erziehbares Kind gegolten. Ich war sowohl hypersentimental als auch jähzornig. Der Vater war für mich eine Respektsperson, aber er war selten zu Hause. Wieviel meine Mutter von meiner sentimentalen Veranlagung verstanden hat, vermag ich nicht $\mathrm{zu}$ sagen. Bei meinen Zornesausbrüchen ließ sie mich einfach in Ruhe, bis ich wieder zugänglich wurde. Es hat mich in meinen Mannesjahren große Mühe und viel Selbstdisziplin gekostet, dieser Veranlagung Herr zu werden. An einige seltene Rückfälle in unbewachten Augenblicken denke ich nicht gern zurück. [. . .]

Bei meinen Jähzornsanfällen schrie ich und stampfte mit den Füßen. Der Jähzorn überfiel mich hauptsächlich, wenn andere nicht so wollten wie ich. Ich erinnere mich an einen Wutausbruch, als mein älterer Bruder etwas nicht tun wollte, wozu ich ihn zu veranlassen suchte. Es war ein gutes Stück Machtwille hinter diesem Jähzorn. Die meisten dieser Anfälle endeten auf die gleiche Weise. Im dunklen Korridor unserer Wohnung stand der Eingangstür gegenüber ein riesiges schwarzes, bis an die Decke reichendes Bücherregal, vor das ein grüner Vorhang gezogen war. Das Regal war vollgestopft mit den grünen Bänden der stenographischen Berichte des Reichstags, mit gebündelten Zeitschriften, Zeitungsjahrgängen und Broschüren. Im untersten Fach dieses Regals hatte ich mir eine Ecke freigemacht. Wenn ich als kleiner Knabe mit Gott und aller Welt und mit mir selber zerfallen war, kroch ich schließlich heimlich in diese Ecke hinter dem grünen Vorhang. Dort saß ich still und zusammengekauert, die Knie bis ans Kinn hochgezogen. Ich hörte, wie man mich suchte und wie nach mir gerufen wurde, aber ich rührte mich nicht. Zunächst tobte ich innerlich uiber die anderen und die Ungerechtigkeit der Welt. Diese Stimmung ging dann all- 
mählich in Selbstbemitleidung über. Schließlich wurde mir weinerlich zumute, und damit kehrte ich langsam wieder zur Normalität zurück und entschloß mich, nicht mehr darauf zu warten, daß man mich finden, bedauern und bitten würde, sondern selber aus dem Schmollwinkel hervorzukommen, als ob nichts geschehen wäre.

$[\ldots]^{3}$

Auf dem großen Bücherregal auf dem Vorplatz standen neben den anderen Schriften die Bände der sozialdemokratischen Unterhaltungszeitschrift „Die Neue Welt". enthielten Romane in Fortsetzungen und daneben Anekdotisches mit bildender Absicht. Ich verschlang alles, da ich lesen gelernt hatte, als ich noch nicht vier Jahre alt war. Ich erinnere mich besonders an einen Roman von Minna Kautsky, der Mutter von Karl Kautsky, mit dem Titel „Der Stefan vom Grillenhof“"5 und an einen zweiten, dessen Titel mir entfallen ist, der aber ebenfalls sozialistische Tendenz hatte. Aber da waren auch Pierre Lotis "Islandfischer", Victor Hugos „1792“ und „Der lachende Mann" und Gerstäckerromane wie „Die Flußpiraten des Mississippi“ und „Die Regulatoren in Arkansas". [. . . $]^{6}$

\section{Schuljahre: Unter dem Einfluß von Naturwissenschaften und Marxismus}

Zwischen meinem sechzehnten und neunzehnten Jahr besuchte ich die neu gegründete Leipziger Oberrealschule, die damals als hypermodern angesehen wurde. Das sachliche Wissen, das sie vermittelte, war sehr groß. Aber noch entscheidender für mich wurde der persönliche Einfluß der beiden Hauptlehrer, des Literatur- und Geschichtslehrers Dr. Robert Riemann und des Mathematik- und Physiklehrers Dr. Beck. Der erstere, ein Sohn des Musiktheoretikers Professor Hugo Riemann, trat nach der Revolution in die Sozialdemokratische Partei ein und veröffentlichte Freidenkerschriften, der zweite war viele Jahre lang der zweite Vorsitzende des Deutschen Monistenbundes. Mit dem ersteren verband mich bald ein freundschaftliches Verhältnis, gegründet auf mein vorlautes Wesen und seine eigene Diskutiersucht. Wir rieben uns aneinander und lernten uns schätzen. Meine Beziehungen zu dem zweiten sind nie über die Grenzen größten Respekts hinausgegangen. Das kam daher, daß er uns moderne Mathematik und Physik als moderne Metaphysik vermittelte, geradezu mit dem Charakter einer Ersatzreligion, wie ich später erkannte. Der Ernst, mit dem er dies unternahm, machte auf seine Schüler großen Eindruck. Wir nannten ihn „der Meister", seine Autorität war bei uns gänzlich unbestritten.

s Kürzung von 21/2 Seiten (Ms. S. 5-7), auf denen die Wohnung der Familie Geyer in der Südstraße und deren Umgebung beschrieben wird.

4 „Die Neue Welt. Illustriertes Unterhaltungsblatt für das Volk“, 1876-1881 in Leipzig, 1882-1886 in Stuttgart erschienen, später in Berlin als Beilage zahlreicher Parteizeitungen mit dem Untertitel „Illustrierte Beilage für Wissenschaft, Belehrung und Unterhaltung“ bis Dez. 1919 fortgesetzt.

5 Minna Kautsky (1837-1912). Der Roman Stefan vom Grillenhof, den auch Marx und Engels schätzten, erschien 1879 in der Zeitschrift „Neue Welt“, selbständig Leipzig 1881. Vgl. Minna Kautsky. Auswahl aus ihrem Werk. Hrsg. von Cäcilia Friedrich, Berlin (O) 1965.

- Kürzung der Seiten Ms. 8-17 mit Schilderungen kindlicher Furcht vor Dunkelheit und Gespenstern, der Beschreibung der Leipziger Schrebergartenidylle und verschiedener Schulerlebnisse. 
Meine Familie lebte in sehr bescheidenen Verhältnissen, mit einem Einkommen, das das Einkommen eines damaligen Amtsrichters nur um ein weniges überstieg. Mein Bruder sollte Jura studieren. Für mich war nach dem Abitur zunächst kein Studium vorgesehen. Mein Vater erblickte schon frühzeitig in mir, seinem jüngeren Sohn, den Fortsetzer seiner politischen Betätigung: denn schon früh hatte er mein Interesse an Parteidingen und Politik erkannt und gesehen, welche Art von Literatur ich mit Eifer in mich hineinschlang, angefangen von den billigen Parteiausgaben der sozialistischen Klassiker, die ich am Ende allesamt beinahe auswendig kannte, bis zu den Bänden von Karl Marx’ Hauptwerk „Das Kapital“. Ich gehöre zu denen, die dies Buch wirklich durchgelesen haben - was bei der abstrusen Terminologie keine leichte Arbeit war - und die wirklich begriffen haben, was es vermitteln wollte. So unterzog ich mich schon in frühen Jahren neben der Schulerziehung, die mir außerordentlich leicht fiel, einer regelrechten Selbsterziehung in sozialistischer Ideologie und Parteigeschichte. Neben den Schriften der Klassiker standen die Schriften von Friedrich Engels' unmittelbaren Schülern Bernstein ${ }^{7}$ und Kautsky ${ }^{8}$ und das wissenschaftlichpolitische Hauptorgan der Partei "Die Neue Zeit“. 9 Erst Jahrzehnte später habe ich begriffen, daß und mit welchen Mitteln einer lebendigen sozialen und politischen Bewegung von den Epigonen der Klassiker eine Ideologie aufgeprägt wurde, die unweigerlich in Konflikt mit der lebendigen Bewegung und ihren Notwendigkeiten kommen mußte - schon weil klassische Theorie und Ideologie versteinert blieben, während die Welt und die sozialen Zustände sich änderten. Der Dualismus zwischen der Doktrin und der Bewegung begann bereits hervorzutreten, als ich noch ein Knabe war, aber sein Wesen ist mir erst viele Jahre später bewußt geworden. Ich war ein absolut gläubiger Marxist, besonders was die materialistische Geschichtsauffassung anbelangte, und ich wußte wirklich, was Marxismus ist. Die moderne Soziologie war damals erst im Entstehen. Auch wenn ich mich im Kreise außermarxistischer Gesellschaftswissenschaft umsah, fand ich nichts, was mich bewogen hätte, an der unbedingt evidenten Wahrheit der maxxistischen Geschichtsphilosophie zu zweifeln. Dazu kam, daß die politische Entwicklung und das gesellschaftliche Leben unter dem wilhelminischen Regime genügend Illustrationsmaterial boten, das als Beweis für die Richtigkeit der marxistischen Theorie benutzt werden konnte. Ich will hier einflechten, daß die Erscheinung, die wir „Klassenjustiz" nannten, mich schon in frühen Jahren in höchste Empörung versetzte. Mein brennender Gerechtigkeitsidealismus und Glaube an die Gleichheit des Rechts und meine ebenso brennende Empörung über offenkundige Ungerechtigkeit in jeder Form gehörten in der Jugend zu den Wurzeln meines Radikalismus.

Die dem Marxismus zu Grunde liegende Anschauung des naturwissenschaftlichen

7 Eduard Bernstein (1850-1932), seit 1872 („Eisenacher") Sozialdemokrat, 1881-1890 Redakteur des "Sozialdemokrat" in Zürich u. London, Verwalter des literarischen Nachlasses Engels', Mitte der 90er Jahre Begründer des Revisionismus, 1902-1928 (mit Unterbrechungen) MdR, 1917 Beitritt zur USPD, 1919 Rücklehr zur SPD.

8 Karl Kautsky (1854-1938), schloß sich 1875 der österr. Sozialdemolkratie an, 1880 Mitarbeiter am „Sozialdemokrat" in Zürich, Freundschaft mit Eduard Bernstein, 1881 Bekanntschaft mit Marx und Engels, 1883-1917 Herausgeber der „Neuen Zeit“, einflußreichster Theoretiker der Sozialdemokratie in der Ara der II. Internationale, Gegner Bernsteins im Revisionismusstreit um 1900, 1917 Mitglied der USPD, Nov./Dez. 1918 Unterstaatssekretär im Auswärtigen Amt, 1922 Rückkehr in die SPD, 1924-1938 lebte K. in Wien, 1938 Emigration nach Amsterdam.

- „Die Neue Zeit. Revue des geistigen und öffentlichen Lebens“ (ab 1901: „Wochenschrift der deutschen Sozialdemokratie"), 1883 von Karl Kautsky und J. H. W. Dietz in Stuttgart gegrïndet, 1883-1917 von Kautsky geleitet, erschien bis 1923 (zuletzt in Berlin). 
Materialismus wurde in meiner Entwicklung verstärkt durch den Einfluß eines führenden Monisten als Lehrer für Mathematik und Physik. So, wie er uns die höhere Mathematik präsentierte, mußtè man unvermeidlich der Anschauung zuneigen, die Heinrich Hertz, der Entdecker der elektrischen Wellen, in die Worte gekleidet hat: „Man kann sich des Gefühls nicht erwehren, daß diese mathematischen Formeln unabhängige Existenz und eigene Intelligenz besitzen, daß sie klüger sind als wir sind, sogar als ihre Entdecker, daß sie uns mehr geben, als ursprünglich in sie hineingelegt wurde." Diese Auffassung, daß die Mathematik eine selbständige außermenschliche Existenz besitzt und nicht einfach eine menschliche Erfindung darstellt, hat mein Denken lange beeinflußt, bis ich mich am Anfang meiner dreißiger Jahre phänomenalistischen Anschauungen zuwandte und mich vom Gesetzesbegriff der älteren Naturwissenschaften unter dem Einfluß der modernen Quantentheorie völlig abwandte. In meiner Schulzeit waren die Hauptsätze der Thermodynamik für mich geradezu metaphysische Glaubenssätze, die einen Weg darstellten, der aus den Schranken menschlicher Erkenntnis hinausführte in die tieferen Geheimnisse des Weltalls.

Ich habe während der Abfassung dieser Erinnerungen nochmals eine Sammlung der letzten Aufsätze von Henri Poincaré, ${ }^{10}$ dem großen französischen Mathematiker, herausgegeben von Wilhelm Ostwald, gelesen. Hier fand ich wieder, was unser Mathematik- und Physiklehrer, der ein großer Verehrer von Poincaré war, uns zu vermitteln suchte: den Sinn für die tieferen Geheimnisse des Weltalls, zusammen mit dem Schutz für die Strenge der Wissenschaft gegen außerwissenschaftliche spekulative Entgleisungen, sowie das ganze Gedankengebäude des deutschen Monistenbundes, ${ }^{11}$ dessen zweiter Vorsitzender mein Mathematiklehrer und dessen Präsident Wilhelm Ostwald ${ }^{12}$ war, an dessen Energielehre ich damals so fest glaubte wie mein Lehrer - an der Schwelle des Zeitalters der Relativitätstheorie, deren Ausbau Poincaré nicht von Einstein, sondern von Minkowski ${ }^{13}$ erwartete. Ostwald besaß in Großbothen bei Leipzig, am Zusammenfluß der Zwickauer und der Freiberger Mulde, ein kleines Landgut. Meine Schulfreunde und ich sind auf unseren Wanderungen oft daran vorbeigekommen, nicht ohne daß wir jedes $\mathrm{Mal}$ in eine Diskussion seiner Theorien verfallen wären.

All das gehörte zu meinen Grundanschauungen gegen Ende meiner Schulzeit, und es wirkte befestigend zurück auf meinen absoluten Glauben an die Selbstevidenz des historischen Materialismus. So, wie ich an ein naturwissenschaftliches Gesetz glaubte, nicht als Erfahrungstatsache, sondern als dem Kosmos inhärent, so glaubte ich mit dem Marxismus das endgültige gesellschaftliche Gesetz und das Gesetz geschichtlicher Bewegung gefunden zu haben, und es kam meiner Ansicht nach nur darauf an, im Einklang mit dem gesellschaftlichen Gesetz seine unbedingte Richtigkeit durch

10 Jules Henri Poincaré (1854-1912), Mathematiker und Physiker (Vetter des Politikers Raymond P.), wissenschaftstheoret. Hauptwerke: Wissenschaft und Hypothese, 1902 (dt. 1904); Der Wert der Wissenschaft, 1905 (dt. 1906).

11 Der Deutsche Monistenbund, 1906 in Jena gegründet (1933 aufgelöst, 1946 wiedergegründet), vertritt eine auf dem Entwicklungsgedanken Ernst Haeckels basierende aufklärerische, religionsfeindliche naturwissenschaftliche Weltanschauung.

12 Der Chemiker, Physiker und Philosoph Wilhelm Ostwald (1853-1932) führte als Hauptvertreter der natur- und kulturphilosophischen Energetik alles Sein und Geschehen auf Erscheinungsformen von Energie zurück.

13 Hermann Minkowski (1864-1909), Mathematiker, lieferte math. Grundlagen der speziellen Relativitätstheorie. 
entsprechende politische Stellungnahme und politisches Handeln aufzuweisen. Das gesellschaftliche Gesetz schien mir eindeutig auf die sozialistische Revolution hinzuweisen, und ich beschloß, in den Gang der Geschichte einzugreifen im Sinne dessen, was meiner Ansicht nach mit unerbittlicher, unentrinnbarer Notwendigkeit kommen mußte. Das bedeutete praktisch Politik und Journalismus in der Sozialdemokratischen Partei als Lebensaufgabe und Existenzgrundlage, wie mein Vater erwartete. Inzwischen hatten Freunde ihn überredet, auch mich bis zur Promotion studieren zu lassen.

Die Erhaltung von zwei Söhnen bis in ihre zwanziger Jahre hinein, die Schulgelder und die Universitätsgebühren bedeuteten für meine Eltern eine große Belastung. Der leidtragende Teil dabei war vor allem meine Schwester, für die nach der Absolvierung der Schulpflicht nichts weiter erzieherisch getan wurde. Auf Taschengeld vom Vater konnte ich schon während meiner Schulzeit nicht rechnen. In meinen letzten beiden Realschuljahren hatte ich mir bereits ansehnliche Taschengelder selber verdient, indem ich Privatstunden für schwächere Schüler gab. Schon während meiner Oberrealschulzeit begann ich zu schreiben, zunächst Dinge belehrenden und feuilletonistischen Inhalts und gelegentlich eine zusammenfassende Darstellung der abgelaufenen Woche im Reichstag für den „Tabakarbeiter". Das gehörte zu den Berufspflichten meines Vaters, der die Sitzungen ja miterlebt hatte. Ich aber las täglich darüber in den großen Zeitungen, und wenn er am Wochenende müde war, überlie $\beta$ er mir die Aufgabe, die ich rascher, und ich glaube besser, erledigte als er, wofür er zu zahlen hatte. Diese journalistischen Exerzitien habe ich auch während meiner Studienzeit fortgesetzt, als ich bereits begonnen hatte, politische Artikel zu schreiben.

In meinen Freundeskreisen hielt ich natürlich mit meinen geschichtsphilosophischen Überzeugungen nicht hinterm Berge. Ich gehörte in der Oberrealschule mit drei Mitschülern einem Freundeskreis an, der viel zusammen wanderte. Auf den Wanderungen pflegte ich zu predigen. Der eine der drei anderen dachte wie ich, der zweite war nicht interessiert, der dritte wehrte sich, fand aber keine gültigen Erwiderungen auf meine Dialektik. Eines Tages erklärte er, daß er mir alles zugebe, was ich über den unvermeidlichen Gang der Geschichte gesagt habe - aber dennoch bleibe dem Menschen noch die freie Wahl, ob er diesen Gang wünschen oder nicht wünschen wolle. Die Richtigkeit der Theorie, die er nicht widerlegen konnte, verpflichte ihn noch nicht, die Richtung einzuschlagen, in die sie weise. Das Argument kam einer Seite meines Wesens entgegen, die damals unter dem Druck der theoretischen Überzeugungen unbedingt Not litt, und in meinem Unterbewußtsein arbeitete es weiter. [... .]

Ich will hier einfügen, daß von Anfang an bei mir neben dem reinen marxistischen Determinismus, der eine ganze Reihe von prominenten sozialdemokratischen Politikern - ich nenne als Beispiel nur Rudolf Hilferding ${ }^{14}$ - an wirklicher politischer Aktivität verhindert hat, eine starke voluntaristische Komponente stand, die allen meinen wichtigen politischen Entscheidungen in der Zukunft die Richtung gegeben hat. Diese Komponente war es auch, die mich veranlaßte, das Machtproblem in Staat,

14 Rudolf Hilferding (1877-1941), ursprünglich Mediziner, marxist. Theoretiker („Das Finanzkapital“, 1910), 1907-1915 Redakteur am Vorwärts, 1917 Mitglied der USPD, 1918-1922 Chefredakteur der „Freiheit“, 1924-1933 MdR, 1923 und 1928/29 Reichsfinanzminister, 1924-1933 Hrsg. der Zeitschrift „Die Gesellschaft" (Nachfolgeorgan der „Neuen Zeit"). 1933 Emigration nach Frankreich. 
Gesellschaft und Revolution bei meinem theoretischen Nachdenken immer stärker in den Vordergrund zu stellen, namentlich als ich dann an der Universität Zeit und Gelegenheit hatte, ihm ernsthaft nachzugehen.

Damit versuchte ich - wenn auch in sehr subjektiver Weise - der revolutionären Illusion, die zur Tradition der Sozialdemokratischen Partei gehörte, einen realen Hintergrund zu geben. In meiner Jugend waren die Überlieferungen der Revolution von 1848/49 unter den älteren Parteimitgliedern noch sehr lebendig, sie färbten nicht nur die Hoffnungen der Partei, sondern auch ihre Sprache. Die sozialdemokratische Ideologie beruhte nicht nur auf diesen Erinnerungen und den Marxschen Revolutionsprophezeiungen. Sie wurde außerdem auf das Stärkste beeinflußt durch die Revolutionen in anderen Ländern. Dem Beispiele von Karl Marx folgend, bestritten Bebel und Liebknech ${ }^{15}$ nach dem deutsch-französischen Kriege ihre Hauptagitation mit der Verherrlichung des Aufstandes der Pariser Kommune, ${ }^{16}$ was sie in heftigen Konflikt nicht nur mit Bismarck, sondern auch dem liberalen Bürgertum brachte. Noch nach dem Ende des Sozialistengesetzes konnte man Spuren dieser Agitation feststellen. Ich habe oft meinen Vater erzählen hören, wie er mit seinen Leipziger Parteifreunden in ihrer Lieblingskneipe in vorgerückter Stunde das Lied anzustimmen pflegte: „Wir sind die Petroleure / das weiß ja jedermann / drum zünden wir die Häuser / mit Petroleum an. / Rechts Petroleum, links Petroleum, Petroleum um und um / laßt die Humpen, frisch voll pumpen / dreimal hoch Petroleum." Hinter diesem auf Bismarck gezielten Spottlied - pour épater le bourgeois - stand die offizielle Stellungnahme der ersten, der Marxschen Internationale zum Kommuneaufstand. Diese Tradition hatte Bismarck zur Begründung des Parteiverbots gedient. Sie wurde nach dem Fall des Sozialistengesetzes in radikalen Parteikreisen weitergetragen, gemeinsam mit den vielen Erzählungen aus der illegalen Zeit, die sich mit der Untergrundbewegung und der Überlistung der Polizei beschäftigten. Das alles war mir von früher Jugend an lebendig durch Erzählungen meines Vaters, die ich später durch eifrige Lektüre der Erinnerungsliteratur ergänzte. Der Fall des Sozialistengesetzes [1. 10.1890] unterstützte die revolutionäre Illusion: denn die Partei glaubte, sie habe Bismarck und das Kaiserreich besiegt. Daß sie in die Periode ihrer neuen Legalität eintrat in einem konsolidierten Reiche mit aufsteigender Wirtschaft und stabilen, zur Versteinerung neigenden gesellschaftlichen Verhältnissen und daß die Entwicklung sich anders vollzog, als die Parteitradition vorausgesagt hatte, wurde von dem radikalen Teil der Partei nicht durchschaut, und so wurde die Revolutionserwartung weiter getragen. Der Glaube, daß die Revolution das Parteiziel darstelle, wurde späterhin auf das Stärkste unterstützt durch die revolutionären Vorgänge der Jahre 1904 und 1905 in Rußland, die nicht nur die ausgesprochene Linke, sondern auch das Zentrum der Partei beeinflußten.

Der Schulfreundeskreis, dem ich angehörte, huldigte der Wandervogelromantik der

15 Wilhelm Liebknecht (1826-1900), Mitgründer der Sozialdemokratischen Arbeiterpartei (Eisenach 1869), als „Parlamentarier und Chefredakteur des Vorwärts" neben Bebel einflußreichster SPD-Führer.

16 Anläßlich der Beratungen über die Annexion Elsaß-Lothringens hatte Bebel am 25. Mai 1871 im Reichstag die Pariser Kommune verteidigt; während der Beratungen über das Sozialistengesetz kam Bismarck am 17. September 1878 darauf zurück: „Sein Verhältnis zur Sozialdemokratie habe sich seit 1871 gewandelt, als die Kommuneverherrlichung Bebels ihn die Gefährlichkeit und Staatsfeindlichkeit der Bewegung habe einsehen lassen." (Wolfgang Pack, Das parlamentarische Ringen um das Sozialistengesetz Bismarcks 1878-1890, Düsseldorf 1961, S. 89.) 
Zeit, wanderte aber nur in der Umgebung Leipzigs. Ich hatte mir angewöhnt, in den Schulferien allein Fußwanderungen im Sächsischen Erzgebirge zu unternehmen, und zwar mit Hilfe der Schülerherbergen, für deren Benutzung man dem Verbande einen sehr niedrigen Jahresbeitrag zahlte. Die Kosten dieser Wanderungen waren so außerordentlich gering, daß ich niemals aus Geldmangel auf eine geplante Wanderung zu verzichten brauchte. Die Wanderungen kamen nicht nur meinem romantischen Naturempfinden entgegen - der Blick von der Kammhöhe des Erzgebirges hinab ins Egertal in der Nähe von Klösterle sprach mich stets mit der gleichen gefühlsmäßigen Qualität an wie einige Bilder von Moritz von Schwind -, sondern gaben mir zugleich einen Einblick in die Armseligkeit des Lebens auf dem Obererzgebirge und stützten damit meine sozialistischen Anschauungen.

Auf literarischem Gebiet hatte ich mich gegen Ende meiner Schulzeit von einer schwärmerischen Goetheverehrung abgewandt. Von meinem vierzehnten Jahre an verkehrte ich in einem literarischen Zirkel, der allwöchentlich seine Zusammenkünfte in dem damals noch existierenden und wie ein Museum erhaltenen Café Schönkopf auf dem Brühl abhielt. Die Mitglieder des Zirkels waren alle direkt oder indirekt mit der Leipziger Arbeiterbewegung verbunden. Die Seele dieser Zusammenkünfte waren zwei Brüder, der eine untersetzt männlich, der andere jünglingshaft schwärmerisch, Söhne eines Schuhmachermeisters in einem kleinen Flecken in der Umgebung Leipzigs. Haus und Werkstatt dieses Schuhmachers, die der Zirkel manchmal besuchte, hätten aus den Zeichnungen Ludwig Richters stammen können. Die beiden hielten sich für angehende große Dichter - sie waren es weder noch sind sie es geworden - und sie betrieben zusammen mit den drei Töchtern des Leipziger Theaterkassierers, der in einer romantischen Mansarde auf dem Brühl wohnte, einen regelrechten Käthchen-Schönkopf-Kult. ${ }^{17}$ Ich war in diesem Kreise von Nutzen, ich hatte nämlich wirklich ungefähr alles von Goethe gelesen. Später ließ ich diesen Zirkel links liegen. Erstens war ich über ihn hinausgewachsen, und zweitens trieben meine literarischen Neigungen, sehr sonderbar für den orthodoxen Marxisten, in die Richtung der Neuromantik.

Wenn ich zurückblicke, wie ich am Ende der Schulzeit war, sehe ich einen jungen Mann voller innerer Widersprüche. Einer Komponente der Bequemlichkeit, Faulheit und sogar Weltmüdigkeit standen ein Drängen nach Aktivität und auch ein außerordentlich starker Geltungsdrang und ein Wille zur Berühmtheit gegenüber. Am Schluß meiner Schulzeit wurde mir nahegelegt, Mathematik oder Chemie zu studieren, und darin lag für mich eine gewisse Lockung. Aber der Zug zur Journalistik und zur Politik, der mir als Sohn eines Politikers und lokalen politischen Führers angeboren war und den mir Leben und Schicksal meiner Familie immer stärker vermittelten, war stärker als alles andere. Ich gehörte zu der ersten Generation der Söhne sozialdemokratischer Parteiführer, die der Tradition des Vaters folgten und nicht gegen sie rebellierten. Diese Haltung hatte bei mir eine stark intellektuelle Grundlage. Es lockten mich nicht nur Ansehen und Stellung des Vaters, ich war vielmehr auf das Stärkste im Banne des marxistischen Gedankengebäudes. Die Schule, die ich zuletzt besucht hatte, war bestrebt, ihre Schüler für den intellektuellen Bedarf der aufsteigenden deutschen Großindustrie auszubilden. Das soziale Idealbild, das sie uns im ganzen vermittelte mit dem Anspruch, daß ihm gleicher Status und minde-

17 Anna Katharina Schönkopf (1746-1810), Tochter eines Leipziger Gastwirts, in die sich Goethe als Student verliebte. 
stens gleiche gesellschaftliche Bedeutung gebühre wie dem höheren Beamtentum, war der Ingenieur. Dies Idealbild wirkte sehr stark auf mich, es entsprach einer mit meinem theoretischen Marxismus in Zusammenhang stehenden technischen Fortschrittsgläubigkeit. Aber ich verarbeitete dies Ideal auf meine eigene Art und Weise: es schwebte mir vor, nicht ein industrieller, sondern ein sozialer Ingenieur zu werden und selbstverständlich in der Sozialdemokratischen Partei.

\section{Studium und Dissertation ïber Verfassungskämpfe in Sachsen 1848}

Da war ich nun Student an der Leipziger Universität und auf meiner Visitenkarte stand: stud. cam. et hist. Staatswissenschaften und Geschichte, neuere und neueste Geschichte erschienen mir für meinen ins Auge gefaßten Beruf als die geeignetsten Fächer. Um ein regelrechtes Philosophiestudium habe ich mich nicht bemüht, denn ich konnte mit einigem Recht behaupten, daß ich die Geschichte der Philosophie von den alten Griechen bis zur Gegenwart sehr eingehend kannte und daß ich mit den neueren und neuesten philosophischen Systemen wenigstens einigermaßen vertraut war. Auch habe ich mich nicht um Logik gekümmert, denn schließlich war ich ein Mathematiker. Es kam hinzu, daß ich den Wert dieser Systeme auf Grund meiner orthodox-marxistischen Anschauungen für sehr relativ hielt. Das Entscheidende in meiner Mentalität beim Beginn des Studiums war, da $\beta$ ich - noch vor Beginn meiner politischen Aktivität - meine theoretischen Grundanschauungen abgeschlossen glaubte und da 3 ich keinen Zweifel an ihnen gestattete.

Ich legte deshalb Wert auf Vorlesungen und Seminarübungen, in denen praktische Dinge zu lernen waren; deshalb trat ich in Karl Büchers ${ }^{18}$ Seminar und in das Seminar des Ordinarius für Verwaltungslehre und Statistik bei Professor Schmid ein. Büchers Vorlesungen über Volkswirtschaftslehre sagten mir gar nichts, dagegen zog ich aus seinen Vorlesungen über Volkswirtschaftspolitik praktischen Nutzen. Bücher selbst war damals schon ziemlich müde. In stärksten Kontakt kam ich mit Professor Johann Plenge, ${ }^{10}$ der im Auftrage Büchers das Seminar leitete und der ganz offensichtlich danach strebte, die Nachfolge Büchers an der Leipziger Universität anzutreten. Er sonderte mich unter den Seminarmitgliedern aus, in der Hoffnung, daß er mich als Bundesgenossen für seine Ideen und durch mich noch andere Bundesgenos. sen gewinnen könnte. Unser Nachhauseweg am Abend nach dem Seminar war für fünfundzwanzig Minuten zu Fuß der gleiche, und jedesmal hämmerte er mir seine Idee ein. Sein Gedankengang war so: die moderne Wirtschaft drängt zur Organisation, zu bewußter Wirtschaftslenkung, und diese Tendenz berührt sich an vielen Punkten mit sozialistischen Anschauungen; denn der Kern und das Ziel aller sozialistischen Anschauungen ist nicht der Klassenkampf, der nur ein Mittel darstellt und zur Kampf- und Übergangsperiode gehört, sondern nach einem sozialistischen Sieg die integral organisierte, bewußt gelenkte Wirtschaft. Aber dazu - so ging sein Gedankengang weiter - gehören erfahrene Volkswirtschaftler, die nicht nur willens, sondern auch auf Grund ihrer Ausbildung und Erfahrung in der Lage sind, diese

18 Karl Bücher (1847-1930), Volkswirt, seit 1892 Ordinarius in Leipzig, Hauptvertreter der jüngeren historischen Schule der Nationalökonomie, Begründer der Zeitungswissenschaft.

19 Johann Plenge (1874-1963), 1910 a. o. Prof. in Leipzig, 1913 Prof. in Münster, 1920 Gründer des staatswiss. Instituts in Münster, 1928-1933 Direktor des Forschungsinstituts für Organisationslehre und Soziologie in Münster. 
Aufgabe zu übernehmen. Er stellte mir vor, daß die Sozialdemokratische Partei in ihrem unteren wie in ihrem höheren Funktionärkreis keine derartigen volkswirtschaftlichen Organisatoren und Wirtschaftsleiter besitze. Die Verwirklichung der sozialistischen Ziele erfordere demnach die Ausbildung solcher Wirtschaftsleiter. Was an den Handelshochschulen geschehe, sei nicht in der richtigen Richtung und gänzlich ungenügend. Und nun kam sein Plan: eine Akademie an einer großen Universität, geleitet von einem Direktor, der diese Entwicklung zum Sozialismus auf wirtschaftsorganisatorischer Grundlage klar vor Augen habe und dessen Lehrplan der Ausbildung dieser Kräfte dienen sollte. Es war klar, daß er mit einem solchen Plan die Nachfolge Büchers an der Leipziger Universität antreten wollte.

Unter den vielen Einwänden, die ich dagegen vorbrachte, stand an erster Stelle, daß er dafür weder die staatliche Genehmigung noch die nötigen Mittel erhalten würde. Auf diesen Einwand entgegnete er, daß in wenigen Jahren die wirkliche Macht bei der Großindustrie liegen werde und daß sie selbst an der Ausbildung qualifizierter Wirtschaftsleiter interessiert sei, da die Praxis und die Familiengeschichte der groBen Industriefamilien lehre, daß wirtschaftsorganisatorisches Talent sich bei den großindustriellen Familien nicht vom Vater auf die Söhne vererbe. Man muß die rheinisch-westfälische Großindustrie dafür interessieren, so sagte er, und wenn es gelänge, würde sie sicher erheblich zur Finanzierung eines solchen Instituts beitragen. Er wisse wohl aus den Seminarübungen und unseren Gesprächen, wie orthodox meine marxistischen Anschauungen seien und wie ich ihnen alles unterstelle: „Aber stellen Sie sich das vor, das muß Sie doch locken, den Sieg des Sozialismus mit dem Gelde der rheinisch-westfälischen Schwerindustrie vorzubereiten." Es lockte mich nicht, weil ich an den Sieg des Sozialismus mit ganz anderen Mitteln glaubte und weil ich wußte, wie groß die Klassenspanne zwischen Bürgertum und Arbeiterschaft war, wie erbittert der Widerstand, ja $\mathrm{Haß}$ gegen alles Sozialistische. Plenges Plan erschien mir daher mit der sozialen Wirklichkeit unvereinbar und selbst seine große Überzeugungskraft konnte mich nicht erschüttern. Aber ich gab zu, daß er im Rahmen der gegenwärtigen Volkswirtschaft ein ernsthaftes Problem aufzeigte, nämlich das des großindustriellen Nachwuchses. Was ich nicht zugab war, daß er auch ein ernsthaftes Entwicklungsproblem der Sozialdemokratischen Partei anrührte, obgleich mir unter seinem Einfluß klar wurde, daß dies Problem wirklich bestand. Aber da es schlecht in meine Vorstellungen hineinpaßte, stellte ich ihm die Anschauung entgegen, daß das Proletariat, diese Kraftquelle der Zukunft, nach dem Siege im Handumdrehen die nötigen qualifizierten Kräfte aus sich selbst entwickeln werde. Diese Anschauung fand in den Schriften sowohl der Klassiker als auch der Epigonen und der radikalen sozialdemokratischen Schriftsteller der Zeit viele Stützen. Späterhin, als Plenge Leiter seines Instituts in Münster war und ich Reichstagsabgeordneter, habe ich manchmal an diese Gespräche gedacht, denn da hatte ich nicht nur die deutschen Arbeiterräte, sondern vor allem auch den Kriegskommunismus in Sowjetrußland aus der Nähe gesehen. Als indessen im Jahre 1915 - ich war bereits Redakteur in Würzburg - Plenges Absicht der Verdrängung Büchers in Leipzig zu häßlichen persönlichen Auseinandersetzungen führte, die in die Öffentlichkeit drangen, nahm ich in einem sehr ausführlichen Artikel in der "Leipziger Volkszeitung“" Stellung gegen Plenge und seine Lieblingspläne und stellte mich auf die Seite Büchers, den ich bei dieser Gelegenheit besuchte.

Das Seminar für Verwaltungslehre und Statistilk war das trockenste, was man sich vorstellen kann, aber hier stürzte ich mich mit Eifer in die Arbeit. Ich wollte lernen, 
was der eigentliche Inhalt staatlicher Verwaltung ist und wie sie funktioniert, immer unter dem Gesichtspunkt der Frage, wo die Macht konzentriert ist und wie sie ausgeübt wird. Allerdings hatte eine Seminararbeit, die ich dort schrieb und die das Bodenproblem großstädtischer Friedhöfe bei rasch wachsender Bevölkerung behandelte, mit dieser Frage wenig zu tun. Wie starr meine damaligen Anschauungen waren, geht aus folgender Episode während meiner mündlichen Doktorprüfung durch Professor Schmid hervor. Er hatte mich über den Volkszählungsbogen examiniert, und ich monierte die Frage nach der Religion; denn der gegenwärtige nicht demokratische Staat habe kein Recht zu dieser Frage. Das interessierte ihn, und in einem angeregten Gespräch legte er mich darauf fest, daß ich bereit wäre, einem voll demokratisierten Staat eine Allmacht zuzugestehen, die an Hobbes' Leviathan erinnerte. Nach 1933 - als ich die totalitären Tendenzen in der sozialistischen Doktrin untersuchte - war diese Erinnerung für mich ein interessanter Illustrationsfall.

Für meine geschichtlichen Studien wurde ich Mitglied im Seminar des Historikers Brandenburg, ${ }^{20}$ des Reichsgründungshistorikers, sowie im Kulturhistorischen Institut von Lamprecht. ${ }^{21}$ Das Institut, im Obergeschoß des Hauses zum Goldenen Bären in der Universitätsstraße untergebracht, war ein sehr angenehmer Arbeitsplatz mit seiner reichhaltigen Bibliothek und seinen Arbeitskojen. Ich habe dort oft meiner Lesewut gefrönt und manches abstruse Buch gelesen. Bei den Übungen, die Professor Salomon ${ }^{22}$ in Lamprechts Institut über politische Parteigeschichte abhielt, habe ich nichts Neues gelernt. Die bedeutendsten Referate, die in diesem Semester in Salomons Seminar gehalten wurden, kamen von dem Dichter Hasenclever ${ }^{23}$ und mir. Er referierte über Lassalles Leben, ich über Jean Baptiste von Schweitzer. Es war alles Stoff aus zweiter und dritter Hand. Hasenclever hielt sich vorzugsweise an Oncken, ich an Gustav Mayer. ${ }^{24}$ Am stärksten erinnere ich mich daran, daß Hasenclever zu seinem Referat in einer roten Weste erschien. Wir beide hielten uns gegenseitig für die einzig wirklichen Intellektuellen unter den Teilnehmern an dieser Übung.

Brandenburgs Seminar war entschieden in viel stärkerem Maße ein Arbeits- und Schulungsplatz. Bei ihm nahm ich ebenfalls an einer UUbung über neuere Parteiengeschichte teil. Er trug mir eine Arbeit über die grundlegenden Differenzen zwischen Lassalleanern und Eisenachern auf. Ich konzentrierte mich dabei auf die Differenzen in der nationalen Frage zwischen den militant großdeutschen Anschauungen von Bebel und Liebknecht und den kleindeutschen oder preußischen der Lassalleaner, aus denen sich Unterschiede zwischen beiden in der Frage Einheit oder Freiheit und in der Beurteilung des Reiches ergeben. Einiges darin überraschte Brandenburg, der einer der Führer der Leipziger Nationalliberalen war, und so kam in diesem sonst trockenen Seminar eine wirkliche Diskussion zwischen ihm und mir zustande. Er hatte angenommen, daß ich als Marxist - als der ich an der ganzen Universität bekannt war - jede Ableitung aus rein politischer Ideologie und rein politischen Moti-

20 Erich Brandenburg (1868-1946), 1899-1937 Ordinarius in Leipzig.

21 Karl Lamprecht (1856-1915), 1891-1915 Ordinarius in Leipzig, löste mit seinem Hauptwerk "Deutsche Geschichte" in den 90er Jahren den heftigen Methodenstreit der dt. Geschichtswissenschaft aus.

22 Felix Salomon (1866-1928), 1901 a. o. Prof. für Neuere Geschichte, ab 1915 Prof. für westeuropäische Geschichte in Leipzig.

23 Walter Hasenclever (1890-1940), expressionistischer Lyriker und Dramatiker, Pazifist, Selbstmord in der Emigration.

24 Hermann Oncken, Ferdinand Lassalle. Zwischen Marx und Bismarck, Stuttgart 1904 (19665); Gustav Mayer, Jean Baptiste von Schweitzer und die Sozialdemokratie, Jena 1909. 
ven ablehnen oder vermeiden würde. Er stürzte sich sofort auf die nationale Problematik. Ich hatte sie in den Vordergrund gestellt, weil sie mir eben bei meinen parteigeschichtlichen Privatstudien aufgegangen war und weil einige Erzählungen meines Vaters ebenfalls in diese Richtung wiesen. Von da ab behielt mich Brandenburg im Auge. Er gab mir als Thema für meine Doktordissertation: „Öffentliche Meinung und Verfassungsentwicklung in Sachsen 184.8 bis 1849." Ich habe später die Dissertation unter dem Titel „Verfassungskämpfe in Sachsen“ als Buch veröffentlicht. ${ }^{25}$

Bei der Vorbereitung des Buches kam mir zugute, daß mein Vater ein ansehnliches Konvolut von Zeitungen und Flugschriften aus diesen Jahren besaß, das er auf den Rat eines Freundes in jungen Jahren außerordentlich billig erstanden hatte. Darunter befand sich nicht nur die letzte Nummer der Neuen Rheinischen Zeitung von Karl Marx, sondern auch, was für mich von größter Wichtigkeit war, ein vollständiges Exemplar der Dresdner Zeitung bis zu ihrem Untergang im Maiaufstand des Jahres 1849. Dies Organ, das den linken Flügel der Demokratischen Partei in Sachsen wie in der Paulskirche vertrat und gegen Schluß völlig unter Bakunins ${ }^{26}$ Einfluß geriet, stellte unter den 1848/49 in Sachsen erscheinenden oder neugegründeten anderen Tageszeitungen für mich das wichtigste Arbeitsmaterial dar. [. . .]

Die Arbeit an der Dissertation hat entschieden mein geschichtliches Wissen als Grundlage für spätere aktuelle Politik erweitert - sie hat mir zum ersten Male gezeigt, wie politische Parteien in Sturmzeiten im täglichen Kampfe in Parlament und Presse um Verfassung und Freiheit miteinander ringen und sich dabei verändern, spalten oder neu zusammenschließen. Die stürmische Atmosphäre dieser Parteikämpfe um Demokratie und Verfassung entsprach meinem eigenen radikalen politischen Temperament. In späteren Jahren ist mir manchmal aufgegangen, daß Stil und Methode meiner Volks- und Parlamentsreden durch die genaue Kenntnis dieser Auseinandersetzungen von 1848 und 184,9 beeinflußt waren. Ich erinnere mich, daß ich im Jahre 1917 als Redakteur an der Leipziger Volkszeitung eines Vormittags binnen weniger Stunden ein umfangreiches Wahlflugblatt für eine Reichstagsnachwahl zu schreiben hatte, das stürmisch und aufpeitschend sein sollte (ich war der einzige, der so rasche Fabrikation leisten konnte). Ich ging nach meiner Wohnung und nahm mir ein Flugblatt aus dem Jahre 1849 vor, las es mit allen seinen kräftigen Beschimpfungen durch und kopierte dann den aggressiv-abrupten Stil mit modernem Inhalt.

$[\ldots]$

Ich will einige Worte hinzufügen über die endgültige Abfassung der Arbeit. Ich bewohnte im gemieteten Hause meiner Eltern in der Leipziger Gartenvorstadt Marienbrunn - neben dem Napoleonstein, dem Völkerschlachtdenkmal und dem Südfriedhof - eine enge Dachkammer, in der gerade genug Platz für den Arbeitstisch, einen Stuhl, das Bett und ein Bücherregal war. Der Arbeitstisch stand in der Mansardenfensternische und auf dem Arbeitstisch ein riesiges, aufstellbares, abgearbeitetes Schreibpult aus dunklem Eichenholz. An diesem Pult schrieb ich meine Dissertation. Das Pult war ein Stück Parteigeschichte. Es war der Arbeitstisch des verstorbenen Reichstagsabgeordneten Julius Motteler $^{27}$ gewesen, als dieser im Exil unter dem

25 Vgl. Bibliographie der Schriften Curt Geyers im Anhang.

26 Michail Alexandrowitsch Bakunin (1814-1876), russischer Anarchist.

27 Julius Motteler (1836-1908), leitete während des Sozialistengesetzes als „Roter Feldpostmeistex“ Druck und Versand des „Sozialdemokrat" in Zürich und London, 1874-1878 und 1903 bis $1907 \mathrm{MdR}$. 
Sozialistengesetz von London aus die Expedition des verbotenen "Sozialdemokrat" nach Deutschland leitete. Er war ein enger Freund meines Vaters. Er und seine Frau, die in der Leipziger Partei allgemein „die Tante“ genannt wurde, sahen in mir eine Hoffnung des Nachwuchses, und die Tante schenkte mir nach dem Tode Mottelers das Pult als Andenken, zusammen mit Stempeln und Siegeln aus der Expedition des illegalen "Sozialdemokrat". An diesem Pulte schrieb ich also meine Arbeit über die Sturmjahre 184.8 und 184.9, und ich war mir dabei immer der Tatsache bewußt, daß ein Zusammenhang zwischen diesen Jahren, der illegalen Zeit des Sozialistengesetzes und der aktuellen politischen Situation bestand. Als ich die Arbeit abgeschlossen hatte, wußte ich, was ich konnte - weit über meine bisherige journalistische Kleinarbeit hinaus.

$[\ldots]^{28}$

In der Leipziger Arbeiterbewegung Eintritt in die Redaktion der Leipziger Volkszeitung

Die politische Blindheit, von der ich geredet habe, erklärt sich zum Teil durch den Kult des Marxismus unter den Leipziger sozialdemokratischen Arbeitern. Er wurde aufrechterhalten und verstärkt durch die Leipziger Volkszeitung, deren theoretische und politische Haltung bestimmt war durch ihre Hauptmitarbeiter Franz Mehring und Rosa Luxemburg. ${ }^{29}$ Unter diesem Einfluß waren die Leipziger Arbeiter sehr "radikal“, das heißt, sie glaubten alle, daß der Sieg der Revolution automatisch eintreten werde, und ferner gebärdeten sie sich bei den inneren Auseinandersetzungen in der Gesamtpartei sehr radikal. Aber ihre Grundhaltung war alles andere als aktivistisch. Sie warteten auf das, was geschehen werde, und waren damit zufrieden. Ihre Belesenheit war erstaunlich, ebenso ihr Stolz darauf, „aufgeklärte Arbeiter“ zu sein. Sie hingen der marxistischen Lehre mit beinahe religiösem Eifer an, glaubten, daß

28 Auf den gekürzten Seiten (Ms. 35-41) schildert Geyer die äußeren Umstände der Abfassung seiner Dissertation, seine Neigung zur Neuromantik und seine Verehrung für Hermann Hesse einerseits und seine Theoriegläubigkeit andererseits. Gegenüber dem Anwachsen des Nationalismus vor dem Ersten Weltkrieg hoffte er auf den Radikalismus einer Mehrheit in der SPD: „In der orthodoxen Anschauung, die auf dem Glauben an den Automatismus des Sieges, herbeigeführt durch die, inneren Widersprüche des kapitalistischen Systems ${ }^{6}$ beruhte, waren der Nationalismus und seine Chance, die große Mehrheit des Volkes zu ergreifen, etwas, das ,nicht sein kann weil nicht sein darf'. Obgleich ich die Schriften der Klassiker, vor allem Friedrich Engels', kannte, in denen die nationalistische Note mit größter Stärke hervortritt, war ich damals in diesem Punkte gewissermaßen seelenblind, obwohl ich die Träume der Paulskirche vom großdeutschen Reich und Friedrich Engels' machtpolitische Konzeption Großdeutschlands kannte ... Ich glaubte an die Theorie, die Theorie mußte stimmen, und so war ich blind gegenüber dem, was ich bei einem geringeren Maß fanatischen Glaubens hätte sehen können. So aber hielt ich hartnäckig an der These fest: Der künftige Gang der Geschichte wird bestimmt durch die Klassenkämpfe im Innern der Nationalstaaten, und die Außenpolitik ist eine abgeleitete Funktion dex inneren, marxistisch gesehenen Entwicklung."

20 Die "Leipziger Volkszeitung - Organ für die Interessen des gesamten werktätigen Volkes“ war, 1894 gegründet, eine der bedeutendsten Tageszeitungen der Sozialdemokratie, in der vor allem auch die Parteilinke zu Wort kam. 1917-1922 war die LVZ neben der (im Nov. 1918 gegründeten) Berliner "Freiheit" das auflagenstärkste und wichtigste Organ der USPD. Franz Mehring (1846-1919), Mitgründer der Spartakusgruppe und der KPD, war von 1901 bis 1907 Chefredakteur. Rosa Luxemburg (1871-1919) war 1901/02 leitend in der Redaktion tätig gewesen. 
sie damit im Besitze der absoluten Wahrheit und der letzten wissenschaftlichen Erkenntnisse seien. Damit hielten sie sich für etwas Besseres als die unaufgeklärten Arbeiter und die Bürger. Ihr Glaube gab ihnen vor sich selber den Status, den ihnen die Gesellschaft des Kaiserreichs verweigerte. In dieser Hinsicht glichen sie viel mehr einer religiösen Sekte, in der die Gläubigen die Lebensform erreicht haben, die sie anstreben. Von diesem Gefühl der Befriedigung und Sättigung aber ging kein Weg zum politischen Aktivismus außer dem Wunsch, die Sozialdemokratie und ihre Organisation immer größer zu machen.

Keine der aktivistischen Tendenzen, die sich vor dem Ersten Weltkrieg in der Sozialdemokratie regten, konnte sie aus dieser Unbeweglichkeit aufrütteln, weder die sächsische Wahlrechtsfrage ${ }^{30}$ noch der Versuch Karl Liebknechts, ${ }^{31}$ eine antimilitaristische Bewegung auf die Beine zu stellen. Sie stimmten zu. Sie demonstrierten auch auf der Straße, wenn sie dazu aufgefordert wurden, aber absolut innerhalb der Grenzen der Legalität, getreu der Parole: Laßt euch nicht provozieren.

Rosa Luxemburg war sicher, Riesenversammlungen und große Ovationen zu erhalten, wenn sie in Leipzig sprach, sowie allgemeine Zustimmung für ihre journalistische Aktivität in der Leipziger Volkszeitung - aber keine praktische Nachfolge, wenn sie versucht hätte, ihre Pläne zur Weckung der Massenaktivität in Leipzig praktisch zu verwirklichen. Karl Lieblnechts Antimilitarismus fand selbst bei der Leipziger Arbeiterjugend wenig Anklang.

Mit dem Beginn meiner Studienzeit hatte ich mich in der Leipziger Arbeiterjugend in ziemliche Aktivität gestürzt. In einem engsten Freundeskreis diskutierten wir oft, wie man sich eine revolutionäre Erhebung gegen das kaiserliche System vorstellen könnte. Das Ergebnis war immer: Im Augenblick überhaupt nicht - aber wenn erst die immanenten Widersprüche des Kapitalismus sich weiter entwickelt hätten, würde sie von selbst kommen. Ich trichterte der Arbeiterjugend in vielen Reden die niederen und höheren Lehren des Marxismus ein und mit ihnen die führenden Ideen des linksradikalen Flügels der Sozialdemokratie. Dazu gehörte in erster Linie der Glaube an den Automatismus des Sieges. Rosa Luxemburg hatte in ihrem Buch „Die Akkumulation des Kapitals" ${ }^{32}$ etwas versucht, wovon Marx schließlich vorsichtig die Finger gelassen hatte, nämlich mathematisch zu beweisen, daß der Kapitalismus in sich selbst ersticken müsse, daß er mit imperialistischen Methoden versuche, diesem Schicksal zu entrinnen, aber daß auch der Imperialismus als das letzte Wort des Kapitalismus mit mathematischer Gewißheit und Naturnotwendigkeit untergehen müsse. Dieser Versuch, die Bewegung künftiger Geschichte abzuleiten aus den angeblich unentrinnbaren Bewegungsgesetzen der kapitalistischen Wirtschaft führte in diesen Jahren zu der grotesken Auslegung, die der damalige Chefredakteur der Leip-

so Im März 1896 war in Sachsen nach preußischem Vorbild das hauptsächlich gegen die Sozialdemokratie gerichtete Dreiklassenwahlrecht eingeführt worden. 1909 wurde es in ein Pluralwahlrecht umgewandelt, das dem einzelnen Wähler je nach Besitz und Bildung bis zu vier Stimmen gab.

31 Karl Liebknecht (1871-1919), Sohn Wilhelm Liebknechts, Rechtsanwalt, 1907 vom Reichsgericht wegen der Broschüre "Militarismus und Antimilitarismus" zu eineinhalb Jahren Festung verurteilt, 1908-1916 Mitglied des preuß. Abgeordnetenhauses, 1912-1917 MdR, Mitgründer des Spartakusbundes, im Januar 1919 ermordet.

32 Rosa Luxemburg, Die Akkumulation des Kapitals. Ein Beitrag zur ökonomischen Erklärung des Imperialismus, Berlin 1913. Neuausgabe Leipzig 1921 mit dem Untertitel: „Oder was die Epigonen aus der Marxschen Theorie gemacht haben". Rosa Luxemburg, Gesammelte Werke, Bd. 5, Berlin (O) 1975. 
ziger Volkszeitung, Dr. Paul Lensch, ${ }^{33}$ ihm gab. Er verkündete, daß der Kapitalismus im eigenen Fett ersticken werde. Also wozu dann Aktivismus?

Neben dieser Lehre vom Imperialismus als letztem Wort des Kapitalismus, der die einzig mögliche Weltpolitik der kapitalistischen Epoche darstelle, stand der Glaube an die Rolle der Arbeitermassen in der Geschichte, nämlich, daß sie instinktiv, auf Grund ihrer Klassenlage, alles besser verstünden als selbst die Theoretiker und daß der Masseninstinkt deshalb den besten Leitstern der Politik darstelle. Mit Hilfe des Vertrauens auf das Vermögen der Massen, eine bestimmte Situation und ihre Funktion in der Entwicklung richtig zu erfassen, bildete Rosa Luxemburg in diesen Jahren ihre Angriffstheorie aus. Da die Massen, wenn sie handeln, richtig handeln, müßten sie eben zum Handeln gebracht werden, eben durch Handeln, beginnend mit Massenstreiks und Zusammenstößen mit behördlichen Organen. Was das letztere anbetrifft, so kann ich nur sagen, daß in diesen Jahren die Leipziger Arbeiter ziemlich polizeifromm waren. Diese mystische Auffassung von der Masse ging Hand in Hand mit der Überzeugung, daß instinktiv und automatisch die Arbeiterschaft der Todfeind von Nationalismus und Imperialismus sei und also immun dagegen. Dieser Masseninstinkt gestattete auch, alle Probleme des sozialistischen Aufbaus und der: Staatsorganisation in einer Revolution beiseite zu schieben mit Hilfe des Glaubens, daß die Arbeiter, die eine so glänzende sozialdemokratische Organisation geschaffen hatten, wohl in der Lage sein würden, innerhalb achtundvierzig Stunden einen fertigen Apparat zur Leitung und Verwaltung der öffentlichen Angelegenheiten aufzustellen. Mehr oder weniger - mit gewissen Nuancen - folgte ich diesen Lehren bei meinen Vorträgen in der Arbeiterjugend. Sie führten mich selbst weiter in der Richtung des Glaubens an folgende Reihenfolge: Kapitalismus - Imperialismus - Krieg Weltrevolution und zur Bejahung der Ansichten Lenins in seiner Schrift „Staat und Revolution".84

Das war alles sehr theoretisch und spekulativ. Die Leipziger Sozialdemokratie war alles andere als eine Partei, die mit zitternder Ungeduld auf die Revolution wartete. Ich war mit ihr aufgewachsen. Ich wußte, wie unrevolutionär die Maifeiern waren und wie spießerhaft es in den Parteikneipen zuging, die mein Vater an Sonntagnachmittagen mit Vorliebe aufsuchte. Den Kern der Partei und der Funktionäre bildeten die Lagerhalter des Konsumvereins. Der Konsumverein und sein Personal wurden von den kleinen wie den großen Geschäftsleuten mit ingrimmigem $\mathrm{Haß}$ bekämpft und unter diesem Druck waren radikale Anschauungen für die Lagerhalterpartei ganz natürlich. Aber revolutionär war sie gar nicht, großzügig auch nicht. Von meiner frühesten Jugend an erfuhr ich durch gelegentliche Ausbrüche meines Vaters die Erbärmlichkeiten und die Intrigen und die Kleinlichkeit des Vereinslebens in der Partei. Eine Begebenheit während der Reichstagswahl des Jahres 1907 ist mir noch lebendig in Erinnerung.

Der Wahlkreis Leipzig-Stadt war im Jahre 1903 von dem Sozialdemokraten Julius Motteler erobert worden. Er gehörte zur alten Garde, er war von Beruf Kaufmann. Mit seinem dichten grauen Haar und den grauen englischen Koteletten und seiner

3s Paul Lensch (1873-1926), Redakteur der LVZ 1902-1913, 1912-1918 MdR, ursprünglich zur Parteilinken gehörend (er lehnte 1914 die Kriegskredite ab), tendierte er immer stärker nach rechts und verließ 1922 die SPD.

34 In ,Staat und Revolution. Die Lehre des Marxismus vom Staat und die Aufgaben des Proletariats in der Revolution", erschienen 1917 (dt. [anonym] 1918), formulierte Lenin die Rolle des Staates innerhalb seiner Revolutionstheorie beim Ubergang vom Kapitalismus zum Kommunismus und postulierte die "Diktatur des Proletariats". 
in England erworbenen zurückhaltenden Vornehmheit sprach er manche Teile der Leipziger Kaufmannschaft sympathisch an. Vor der Wahl von 1907 beschlossen die Leipziger Parteifunktionäre, geführt von der Lagerhalterpartei, ihn abzusägen, angeblich wegen Überalterung. Sie stellten einen Konsumvereinslagerhalter als Kandidaten auf. Mein Vater war empört und prophezeite Unheil. Die Partei verlor den Wahlkreis in eklatanter Niederlage.

Am Abend und in der Nacht des Wahltages war ich mit meinem Vater in einem der großen Leipziger Versammlungssäle, in denen die Parteigenossen an den Biertischen das Ergebnis der Wahl abwarteten. Ich saß mit dem Vater auf dem Podium. Die Niederlage der Partei im ganzen Reich ${ }^{35}$ war schon früh sichtbar. Ich habe niemals die Stimmung dieses schlecht erleuchteten Versammlungssaales vergessen. Sie wurde düsterer und düsterer und manche weinten. Von Zeit zu Zeit hielt mein Vater, dessen Wiederwahl frühzeitig feststand, ermutigende Ansprachen. (Späterhin habe ich im gleichen Saal einige meiner revolutionärsten Reden gehalten.) Dann kam das Ergebnis von Leipzig-Stadt: 25000 Stimmen für den Nationalliberalen [Johannes Junck], 15000 für den Sozialdemokraten. Es fiel wie ein Donnerschlag auf die Versammlung. Ehe mein Vater zu einer tröstenden Rede ansetzte, nahm er mich beiseite und sagte: „Hier ist eine Mark. Sieh zu, wie du am raschesten zu Motteler kommst und erzähle ihm das Ergebnis. Er wird sich freuen. "Ich folgte dem Befehl, aber meine Jugend war angewidert durch die Intrige in der Partei, die zu diesem Ergebnis und zu dieser Äußerung meines Vaters geführt hatte. Ich fuhr zu Motteler, wurde auf das Freundlichste von der "Tante" empfangen und berichtete ihm dann. Er nahm mit einem tiefen Atemzuge davon Kenntnis, war aber zu vornehm, um sich zu äußern.

Vor den Reichstagswahlen von 1912 zog die Leipziger Organisation die Lehre aus den Erfahrungen von 1907 und berief als Kandidaten den Kaufmann Max Cohen ${ }^{\mathbf{3 6}}$ aus Frankfurt am Main. Wie seine weitere politische Entwicklung bestätigte, gehörte er zur Rechten in der Partei, er war kein Radikaler. Aber er hatte offenbar das Bedürfnis, dem Radikalismus der Leipziger Arbeiter entgegenzukommen, während die Vornehmheit und Exklusivität seiner Frau ihm Ansehen beim Bürgertum verlieh. Dies Bedürfnis führte zu einem Zwischenfall, an den ich mich ebenfalls wohl erinnere.

Kurz vor dem Wahltermin sprach Cohen im größten Leipziger Versammlungssaal. Der kreisrunde Raum war bis zum Bersten gefüllt. Ich saß auf dem Podium neben meinem Vater, auf der anderen Seite meines Vaters, am Ende des langen Vorstandstisches, saß der überwachende Beamte, der Polizeidirektor von Leipzig in Person. Cohen sprach von einem erhöhten Rednerpult vor dem Vorstandstisch aus. Er sprach über die Reaktion in den Ländern und sagte schließlich: „Diese Fürsten und Herzöge und Großherzöge, diese Wilhelme und Auguste, und wie weiter diese .. ." Die natürliche Fortsetzung war selbstverständlich : "Herren alle genannt werden." Aber

35 Trotz hoher Stimmengewinne verlor die SPD bei den Reichstagswahlen 1907 aufgrund des Mehrheitswahlrechts mit Stichwahlsystem und der Wahlkreiseinteilung insgesamt fast die Hälfte ihrer Mandate.

36 Max Cohen(-Reuß) (1876-1963), seit 1902 SPD-Mitglied, 1909-1914 Stadtverordneter in Franlsfurt/M., unterlag dem nationalliberalen Kandidaten Johannes Junck, wurde aber in einer Nachwahl im Dezember 1912 MdR für den Wahlkreis Reuß ä. L., den er bis 1918 im Reichstag vertrat. 1918 Mitglied des Berliner Vollzugsrats, 1918/19 stellv. Vorsitzender des Zentralrats, Vorsitzender des (II.) Zentralrats, 1920-1933 Mitglied des Vorläufigen Reichswirtschaftsrats, 1934 Emigration nach Frankreich. 
er suchte nach dem Worte "diese" sichtlich nach einem Kraftwort und stieß dann hervor: „Lumpen alle genannt werden.“ Er machte damit auf die Zuhörer keinen Eindruck, wohl aber geriet der Polizeidirektor in größte Verlegenheit. Er wandte sich an meinen Vater und fragte: „Herr Geyer, haben Sie das gehört?" Mein Vater sagte mit unbewegtem Gesicht: "Was meinen Sie, ich habe gerade nicht zugehört.." „Aber Sie müssen doch gehört haben, daß Ihr Kandidat eben die deutschen Fürsten Lumpen genannt hat!" Mein Vater blieb dabei, daß er gerade nicht hingehört habe. Nachdem die Versammlung aus war, beklagte sich der Polizeidirektor bei meinem Vater: „Daß mir das passieren muß! Wir sind doch immer so gut miteinander ausgekommen, Herr Geyer, und haben nie große Schwierigkeiten gehabt. Aber das ist doch unerhört, das haben viele Tausende gehört, und ich muß amtliche Anzeige wegen Majestätsbeleidigung erstatten." Mein Vater blieb dabei, er habe nichts gehört, vielleicht habe sich der Herr Polizeidirektor auch geirrt. Als wir allein waren, sprach mein Vater seine Empörung über Cohens unechte, gemachte Provokation der Polizei aus. Die Parteileitung teilte seine Empörung. Der Vorfall wie die Klagen des Polizeidirektors warfen ein interessantes Licht auf den Radikalismus der Leipziger Arbeiter, für die es selbstverständlich war, daß der Polizei keinerlei Anlaß zum Einschreiten gegeben werden dürfe.

[...]

Nach der zweiten Stichwahl der Reichstagswahl von 1912 berichtete ich nachts meinem Vater, der bereits im Bett lag, das Endergebnis, eine sozialdemokratische Fraktion von $110 \mathrm{Abgeordneten.}{ }^{37} \mathrm{Er}$ sagte: „Das ist zuviel." Als ich ihn fragte, warum, setzte er mir auseinander, daß diese Fraktion, deren Stärke durch ein Wahlabkommen mit den Fortschrittlern erreicht worden war, notwendig eine Verstärkung der rechten Tendenz in der Partei mit sich bringen müßte.

Einer meiner besten Freunde, die ich mir durch die Tätigkeit in der Arbeiterjugend gewann, war ein kleiner Buchhalter, einige Jahre älter als ich und verwachsen. Er hieß Oskar Wagner. In seinem Zimmer hatte er eine Bibliothek sozialistischer Bücher und Schriften und allgemeinwissenschaftliche Bücher, die einem Professor Ehre gemacht hätte. Er war einer der gebildetsten und vor allem der besten Menschen, die ich je kennengelernt habe. Er besa $\beta$ in höchstem Maße das, was eine kleine Elite unter den sozialdemokratischen Arbeitern Leipzigs auszeichnete, nicht nur den Drang nach Bildung, sondern die Verwirklichung des „liebe deinen Nächsten wie dich selbst", jene Humanität und Moralität, die sie veranlaßte, ihr Leben nach ihren Grundsätzen zu führen. Er liebte die Partei wie ein Sektierer seine Sekte. Er übertrug diese absolute Ergebenheit auf mich persönlich, er wurde zum Treuesten meiner Gefolgschaft; denn wirkliche Gefolgschaft war es, die ich damals sammelte. Er vermittelte mir die Stimmungen der Arbeiter im Betrieb wie die Stimmungen unter der breiteren Masse der unteren Parteifunktionäre. Häufig war ich in seiner Wohnung in einem der industriellen westlichen Vororte L.eipzigs, in die mich meine Tätigkeit in der Arbeiterjugend ohnehin führte.

Neben dieser Tätigkeit und neben dem Studium hatte ich bereits am Ende meiner Schulzeit begonnen, systematisch englisch zu lesen und zwar mit Hilfe der billigen Tauchnitzausgaben. Hier stieß ich nun auf die englische politische Welt, die mir am

${ }^{37}$ Bei den Hauptwahlen am 12.1.1912 erhielt die SPD 64. Mandate, bei den anschließenden Stichwahlen gewann sie weitere 46 Sitze und zog mit 110 Abgeordneten $(34,8 \%$ der abgegebenen Stimmen) als stärkste Fraktion in den Reichstag. Die linksliberale Fortschrittliche Volkspartei erhielt insgesamt 41 Mandate. 
Ende meiner Studienzeit am stärksten vermittelt wurde durch den Schlüsselroman „Der neue Machiavelli“" von H. G. Wells. ${ }^{38}$ Dieser Roman stellt eigentlich ein Kompendium der englischen politischen Gesellschaft und des parlamentarischen Lebens in einer alten entwickelten Demokratie dar und daneben eine Psychologie des Parteilebens und -getriebes. Der Eindruck, den dieser Roman auf mich machte, war sehr stark. Er hat viele Jahre vorgehalten, und was ich daraus gelernt habe, hat mir später die Loslösung von der marxistischen Dolktrin erleichtert. Zwei weitere Bücher, „Politik und menschliche Natur“" von Graham Wallas und „Die Demokratie in England" von dem schwedischen Professor Gustav Steffen verstärkten diesen Eindruck. ${ }^{39}$

Diese formativen Jahre näherten sich ihrem Ende, als meine Dissertation angenommen war und der Termin für die mündliche Prüfung für den 5. Mai 1914 festgesetzt wurde. Die bis zu diesem Termin verbleibenden vier Wochen verwandte ich zum Büffeln, was mir bei der Prüfung wirklich zugute kam. Die Prüfenden waren die Professoren Brandenburg, Bücher und Schmid. Neben anderen Dingen befragte mich Bücher eingehend über das deutsche Steuersystem, vor allem die indirekten Steuern. Ich zählte ihm die Liste der indirekten Steuern der Reihe nach auf. Er nickte beifällig mit dem Kopf und sagte mit mildem Lächeln: „Sie haben eine vergessen." Ich dachte nach und sagte dann: „Ich glaube nicht, Herr Professor." "Doch. Sie haben die Tabaksteuer vergessen." Und das freute ihn als großer Spaß. Mein Vater war Spezialist für die Tabaksteuer im Reichstag, und ich wußte natürlich alles darüber. Nach der letzten Prüfung durch Professor Schmid eröffnete mir der Dekan der Universität noch am gleichen Abend, daß ich die Doktorprüfung summa cum laude bestanden habe. [...]

Nun trat die Frage an mich heran, was ich weiter tun sollte. Es war vereinbart worden, daß ich als Volontär in die Redaktion der Leipziger Volkszeitung eintreten sollte. Die Frage für mich war, ob ich weiteres Studium und die Arbeit in den Seminaren aufgeben und mich völlig in den Journalismus stürzen oder gleichzeitig weiterstudieren sollte, möglicherweise bis zu einer Habilitationsschrift. Ich nahm mir das letztere vor, aber schon nach vier Wochen kam ich davon ab.

Neben der Redaktionstätigkeit an der Leipziger Volkszeitung betrieb ich indessen noch ein Privatstudium. Ich war mir im klaren darüber, daß mir bei aller Kenntnis neuester Geschichte noch ein erhebliches $\mathrm{Ma} ß$ von Personenkenntnis und genauer Kenntnis der umstrittenen politischen Problematik der jüngsten fünf bis zehn Jahre fehlte. Ich stürzte mich deshalb auf die stenographischen Berichte des Reichstags, die mein Vater besaß, und las genau nicht nur vergangene Debatten nach, sondern auch die Anlagen dazu. Ebenso las ich auf das genaueste zehn Jahrgänge der „Preußischen Jahrbücher" von Hans Delbrück und der "Grenzboten" ,40 um die Personen,

38 "The New Machiavelli" war 1911 erschienen, zur Wirkung des Romans vgl. Patrick Parrinder (Ed.), H. G. Wells. The critical Heritage, London 1972, S. $181 \mathrm{ff}$.

30 Gemeint ist wohl: Gustav Steffen, Das Problem der Demokratie, Jena 1912.

40 Der Historiker Hans Delbrück (1848-1929) war von 1889-1919 Hexausgeber der 1858 gegründeten „Preußischen Jahrbücher. Berliner Monatsschrift für Politik, Geschichte und Literatur", die er in national- und sozialpolitisch orientierter konservativer Richtung profilierte. Delbrück war 1882-1885 Abgeordneter der Freikonservativen Partei im preuß. Abgeordnetenhaus, 1884-1890 auch MdR. - „Die Grenzboten - Wochenschrift für Politik, Literatur und Kunst" 1841 in Brüssel zur Pflege der Beziehungen zwischen dem flämischen und dem deutschen Liberalismus gegründet, erschienen von 1842-1923 in Leipzig. Die Zeitschrift war seit 1898 konservativ. 
die Ansichten und Argumente der anderen Seite kennenzulernen. Das war eine große Anstrengung, die viel Selbstdisziplin erforderte. Aber dieser Akt des Perfektionismus hat mir nichts geschadet. Ich war danach absolut sicher, daß mir in journalistischer Arbeit nichts begegnen konnte, was ich nicht kannte und daß ich nun als Wissender inmitten der aktuellen Politik stand. Erst später habe ich die Weisheit des Spruches verstanden : „Ein Journalist weiß alles. Er lernt alles von Fall zu Fall.“ In der Leipziger Volkszeitung arbeitete ich unter dem Chefredakteur Hans Block ${ }^{41}$ neben den politischen Redakteuren Eugen Prager, ${ }^{42}$ Dr. Paul Hertz ${ }^{43}$ und Alfred Herre. ${ }^{44}$ Der letztere war ein Arbeiterjournalist, kein Intellektueller. [. . . ]

\section{Kriegsausbruch 1914: Sozialismus zwischen Klassenbewußtsein und Nationalismus}

Ich erlebte den Kriegsausbruch als Volontär an der Leipziger Volkszeitung. Seit Jahren hatte ich die weltpolitischen Krisen, die ihm vorangingen, mit wachsendem Verständnis verfolgt. Ich kannte die Diskussionen der Internationalen Sozialistenkongresse über das Problem des Verhaltens sozialistischer Parteien im Kriegsfall. Vor allem kannte ich die einzig klare außenpolitische Linie, welche die Partei, der Tradition der Klassiker folgend, herausgearbeitet hatte, nämlich die Feinderklärung gegen Rußland. Sie wurde begründet mit der Existenz des zaristischen Despotismus, aber ihre wahren Wurzeln lagen tiefer. In den frühen Schriften von Friedrich Engels war bereits sein Haß und der von Karl Marx gegen die slawischen Völker hervorgetreten. Auch hatte in der praktischen Politik der Partei in den letzten Jahren die Begründung des Reichskanzlers von Bethmann Hollweg ${ }^{45}$ für die Heeresvorlagen, welche die panslawistische Gefahr und die Bedrolhung durch den russischen Koloß ins Feld führte, keinen Widerspruch von der Mehrheit der Reichstagsfraktion und der Parteitagsmehrheit erfahren. Dennoch blieb für mich die Frage vollständig offen, ob das Klassenbewußtsein der Arbeiter oder der Nationalismus sich als stärker erweisen würde. Da war weiter die Tatsache, daß die Partei sich ihren Anhängern gegenüber seit Jahren als die Partei gegen den Krieg oder, wenn man so will, als die Kriegsverhinderungspartei ausgegeben hatte.

41 Hans Block (1870 ）, Buchhändler, 1893-1899 Redakteur der „Rhein.-Westfäl. Arbeiterzeitung“, 1899-1906 „Sächsische Arbeiterzeitung Dresden“, 1906-1911 „Vorwärts“, 1.4. 1911-1922 (?) Redakteur der LVZ, Mai 1923 Pressechef in der Nachrichtenstelle der Sächsischen Staatskanzlei.

42 Eugen Prager (1876- ), Handlungsgehilfe, 1904-1906 Mitarbeiter der „Volkswacht" Breslau, 1906-1907 Redakteur am "Offenbacher Abendblatt", 1907-1911 an der „Rhein. Zeitung“" Köln, 1911-1914 „Tribüne“ Erfurt, April 1914-Mai 1919 LVZ, Mai 1919-April 1922 „Freiheit" Berlin, bis 1922 Mitglied der USPD, ab 1.1.1925 Redakteur bei der SPD-Reichstagsfraktion.

43 Paul Hertz (1888-1961), seit 1905 SPD-Mitglied, zwischen Studium (Dr. rer. pol.) und Kriegsdienst 1914 kurze Zeit Redakteur der LVZ, 1917-1922 Mitglied der USPD (rechter Flügel), 1918-1922 politischer Redakteur der „Freiheit“, 1920-1933 MdR, 1933 Emigration über Prag und Paris nach USA, 1933-1938 Mitglied des emigxierten SPD-Vorstands, dann der Gruppe „Neu Beginnen“, 1951-1961 Senator (für Marshall-Plan bzw. für Wirtschaft und Kredit) in Berlin.

44 Alfred Herre (1875-1953), Metallarbeiter, 1899-1901 Lokomotivheizer, 1905-1921 und 1924 bis 1929 (?) Redalteur d. LVZ, 1921-1922 Schulleiter d. Heimvolkshochschule Tinz.

45 Theobald von Bethmann Hollweg (1856-1921), Reichskanzler und preuß. Ministerpräsident 1909-1917. 
Kurz vor dem Kriegsausbruch war die Problematik direkt an mich herangetreten. Ich mußte für die Zeitung das im Jahre 1914 erschienene Buch J. J. Ruedorffers „Grundzüge der Weltpolitik“46 kritisch besprechen. In diesem Buch wurde ausführlich dargelegt, daß die Sozialdemokratische Partei durch ihre politische Praxis stillschweigend, im Widerspruch zu ihrer auf das Klasseninteresse gegründeten internationalistischen Ideologie, anerkannt habe, daß die nationalen Bande stärker seien als die Klassenbande und daß die Regierungen auf den Internationalismus ihrer sozialistischen Parteien keine Rücksicht zu nehmen brauchten, wenn sie an das Nationalgefühl der Nation appellieren müßten. Die einzige Wirkung des sozialistischen Internationalismus sei, daß die Regierungen sorglich auf die Deckung durch das Nationalgefühl zu achten hätten. Und weiterhin, daß der nationale Drang nicht mehr nur das Empfinden der Gebildeten, des Adels und des Bürgertums beherrsche, sondern im Volke unaufhörlich wachse und nur schlummernd auf den Ruf der Ereignisse warte. Das alles erschien mir vom Standpunkt meiner marxistischen Dogmatik und meines Glaubens an den sozialdemokratischen Radikalismus als gänzlich ungeheuerlich - aber dann auch wieder zu Nachdenken und Überprüfung provozierend. Ich beschränkte mich darauf, in der Polemik darauf zu verweisen, daß man der kaiserlichen Regierung nach allen Erfahrungen in internationalen Krisen mit gerechtfertigtem Verdacht auf die Fäuste sehen müßte und beschuldigte den Verfasser, daß er der Regierung empfehle, das Volk durch einen nationalistischen Rausch zu täuschen. Ich erblickte in diesem Buch einen Generalangriff auf die marxistische Psychologie und brachte dies zum Ausdruck. Dies Buch gehörte zu den Erschütterungen, die meiner starren Dogmatik versetzt wurden. Für die Diskussion zwischen der äußersten Linken und dem Zentrum der Sozialdemokratischen Partei über die Frage, wie sich die Masse der deutschen Arbeiterschaft, die Sozialdemokraten eingeschlossen, beim Ausbruch eines Krieges verhalten würde, unterstützte das Buch Ausführungen, die Karl Kautsky über die psychologischen Möglichkeiten der Massenhaltung in der „Neuen Zeit“ veröffentlicht hatte. ${ }^{47}$ In dieser Diskussion lehnten meine Freunde und ich den Gedanken, daß die Massen den Krieg bejahen könnten, geradczu mit Entrüstung ab.

Als sich nach dem Attentat von Sarajewo [28.6.1914] die ersten ernsthaften Anzeichen der Kriegsgefahr zeigten, diskutierten wir in der Redaktion über eben diese Frage, ob nämlich der Krieg einen Rückschlag gegen alles bedeuten würde, was der Radikalismus erwartete und gelehrt hatte, oder den Beginn der Revolution. Die Älteren neigten zu der ersteren Ansicht, nur die Jüngeren, mich eingeschlossen, zu der letzteren. Ich wußte aber auf Grund einer Befragung meiner engeren Freunde im wehrpflichtigen Alter, daß keiner von ihnen auch nur von weitem daran dachte, sich einem Mobilmachungsbefehl zu entziehen. Vor mir selber stand die Frage nicht. Ich war vor Jahren wegen außerordentlicher Kurzsichtigkeit als dauernd dienstunfähig ausgemustert worden.

Die letzten Tage vor Kriegsausbruch in der Redaktion sind tief in mein Gedächtnis eingegraben: die wachsende Spannung und Erregung, der Ansturm der Telegramme mit ihren Widersprüchen, die erregten Telefonanrufe unseres Berliner Korrespondenten, das Hin und Her im letzten Augenblick zwischen dem Zustand drohender

46 J. J. Ruedorffer: Grundzüge der Weltpolitik in der Gegenwart, Stuttgart 1914. Hinter dem Pseudonym Ruedorffer verbarg sich Kurt Riezler (1882-1955); vgl. Kurt Riezler, Tagebücher, Aufsätze, Dokumente. Eingel. u. hrsgg. von Karl Dietrich Erdmann, Göttingen 1972, S. 21. 47 Karl Kautsky, Die Aktion dex Masse, in: Die Neue Zeit 30/I (1911), S. 43-49, 77-84, 106-117. 
Kriegsgefahr und dem Mobilmachungsbefehl, alles hatte damals traumhafte Wirklichkeit, man gruppierte Nachrichten und gruppierte sie um, bis schließlich der Mobilmachungsbefehl [1.8.1914] veröffentlicht wurde.

Nachdem die Nummer mit dieser Nachricht abgeschlossen war, ging ich von der Tauchaer Straße zu Fuß nach dem Augustusplatz, dem größten Platz Leipzigs, zwischen dem Neuen Theater und der Gemäldegalerie. Der ungeheure Platz war erfüllt von einer kriegsbegeisterten, jubelnden Menschenmenge. Ich habe später diesen Platz ähnlich dicht angefüllt gesehen nur bei meinen dort abgehaltenen revolutionären Massenversammlungen. Es war unschwer zu erkennen, daß diese Masse alle Parteien und Klassen umfaßte, unsere eigenen Parteimitglieder eingeschlossen. Am Rande traf ich mehrere meiner Freunde, die gleich mir fassungslos dieser Explosion von kriegerischer Volksleidenschaft zusahen. Wir waren tief erschüttert; denn unsere Welt, so wie unsere Doktrin sie uns gezeigt hatte, schien über unseren Köpfen zusammenzufallen. Der Kontrast war riesengroß. Zwei Tage zuvor hatte die Partei eine Straßendemonstration für den Frieden veranstaltet mit riesiger, alles Gewohnte überschreitender Beteiligung. Die Demonstranten fluteten am Abend und beim Einbruch der Nacht durch sämtliche Straßen der inneren Stadt, diesmal über alle Polizeianweisungen hinweggehend. In dieser Demonstration marschierte die Arbeiterjugend, zum Teil mit Fackeln, und während die Menschenmassen riefen: „Nieder mit dem Krieg, wir wollen Frieden", sang die Arbeiterjugend die verbotenen Zeilen des Parteiliedes: „Wohlan, wohlan und sei's zum Tod; denn unsere Fahn' ist rot.“ Wohl hätte man diesen Abend als Stütze der Anschauung ansehen können, daß die Massenreaktion eine Revolution gegen den Krieg sein würde. Und nun diese begeisterte spontane Kundgebung für den Krieg durch alle Bevölkerungsschichten. Es war eine erstklassige Lektion über Massenpsychologie. Ich verbrachte den Abend und den folgenden Tag damit, meine Freunde aufzusuchen, die sofort einrücken mußten, von ihnen Abschied zu nehmen und zu versprechen, daß wir in Verbindung bleiben würden.

Mein Vater, der nach Berlin fuhr, warnte mich vor Illusionen über eine radikale Haltung der Reichstagsfraktion. Er gehörte zu den vierzehn, die am 4. August in der Fraktion gegen die Bewilligung der Kriegskredite opponierten. ${ }^{48}$ All die Differenzen doktrinärer und ideologischer Art sowie die des politischen Wollens, wurden in der Folgezeit auf die Frage: Für oder wider Bewilligung von Kriegskrediten polarisiert.

Ich sah mich plötzlich in einer anderen Welt. Alle Illusionen, Glied einer machtvollen Richtung für den revolutionären Sozialismus zu sein, deren Sieg durch die Geschichte selbst garantiert war, verflogen. Die Massen, an die ich geglaubt hatte und die ich zu kennen glaubte, gingen ihren eigenen Weg. Das Ergebnis war keineswegs, da $\beta$ ich in Verzweiflung fiel und wie Rosa Luxemburg ausrief: „O, nun ist alles verloren“, sondern das Gefühl: „Nun erst recht!" - verbunden mit dem Glauben, daß ich selbst einer der wenigen sei, die berufen seien, den Kampf mit der Woge des Nationalismus aufzunehmen. Ich habe früher bereits berichtet, daß bei mir neben

48 In der Fraktionssitzung am 3. (nicht 4.) August 1914 stimmten 78 Abgeordnete für, 14 gegen die Kriegskredite. Namentlich stehen zweifelsfrei nur 12 Mitglieder der SPD-Fraktion fest, darunter F. Geyer, Haase, Ledebour, Liebknecht. Vgl. dazu: E. Matthias u. E. Pikart (Bearb.), Die Reichstagsfraktion der deutschen Sozialdemokratie 1898-1918, Düsseldorf 1966, T.1, S. CLXXXVII, u. T. 2, S.3. Im Plenum des Reichstags stimmte die SPD am 4.8.1914 geschlossen für die Kriegskredite. 
dem marxistischen Determinismus eine starke voluntaristische Komponente vorhanden war, die mich veranlaßte, dem Problem der Macht nachzugehen. Sie trat nun in den Vordergrund; denn meine Überlegungen gingen dahin, daß die Massen nicht stark genug geführt worden waren und daß dies geändert werden müßte. Über die Zielrichtung dieser starken Führung war ich mir völlig im klaren, sie mußte zur sozialistischen Revolution hinführen. Sie erschien im Augenblick entfernter als jemals zuvor - aber im Verlaufe des Krieges würden Situationen entstehen, in denen die Möglichkeit revolutionärer Aktivität nicht mehr so entfernt scheinen würde.

Es war eine Flucht in die revolutionäre Illusion mit allen Konsequenzen, weit über meine bisherige Bejahung des Glaubens an die Revolution hinaus. Ich empfand, daß ich damit zunächst sehr allein stand, aber gerade das verstärkte meinen Entschluß, den ich für mich selber feierlich formulierte, diesem Ziel zu dienen. Aber natürlich nicht in der Masse mit der Masse, sondern als Wecker und Führer des Massenwillens. Das verstärkte das Gefühl, ein Außenseiter zu sein, der sich gegen die Bewegung stellte, die im Augenblick das ganze Volk erfaßt hatte. Ich könnte sagen: aber ich beschloß, mich außerhalb zu stellen und die Partei der Revolution zu ergreifen, so wie die Veteranen von 1848 und 1849, Marx und Engels und ihre Freunde im Exil in England ständig in der Erwartung einer Wiederbelebung der Revolution in Deutschland gelebt hatten. Es war eine Flucht aus der Realität der Gegenwart, und so trieb ich im Laufe der nächsten beiden Jahre immer stärker in Anschauungen hinein, wie sie von Leo Trotzki in seiner Schrift „Der Krieg und die Internationale“ [Zürich 1914] niedergelegt wurden.

Ich erlebte, daß ein Teil meiner Freunde stark patriotisch bewegt war, so alle meine alten Schulfreunde. Ich, der ich von vornherein gemeinsam mit meinen nächsten politischen Freunden der kaiserlichen Regierung die Kriegsschuld zuschrieb, stand dem völlig kühl gegenüber. Vor mir stand niemals die Frage, ob ich mit der großen Masse konform gehen sollte. Dagegen überlegte ich mir, ob ich eine abwartende Haltung einnehmen könnte. Mit meinen marxistisch philosophischen Anschauungen wäre es vercinbar gewesen, wenn ich mir gesagt hätte: Nichts hängt von individuellen Entscheidungen ab, warum soll ich mich also entscheiden - und darüber hinausgehend: warum soll gerade ich mich entscheiden? Ich konnte versuchen, die massenpsychologischen Vorgänge bei Kriegsausbruch mit der Doktrin zu vereinbaren, was in jeder Hinsicht die bequemere Entscheidung gewesen wäre und im Einklang mit dem indolenten Zug meines Wesens. So fragte ich mich: Warum ich? Die Antwort der voluntaristischen Seite meines Wesens bestand in der Gegenfrage: Wenn ich mich der Aufgabe offener Opposition entziehe, kann das nicht jeder andere auch mit dem gleichen Recht? Ich stellte dann folgende Überlegung an: Wenn wir die Frage der Kriegsschuld aufwerfen und die Schuld der kaiserlichen Regierung zuschreiben, anerkennen wir, daß der Gang geschichtlicher Ereignisse von Personen und individuellen Entscheidungen abhängt, also hängt er auch von unseren eigenen individuellen Entscheidungen ab. Im Grunde genommen handelte es sich darum, ob ich den Ereignissen gegenüber die Haltung eines Historikers und Soziologen oder die eines Politikers einnehmen sollte. Bei diesen durcheinander gehenden Erwägungen, die alle mehr oder weniger mit der marxistischen Dogmatik zusammenhingen, stellte ich mir eine einzige Frage nicht - nämlich die Frage, ob ich nicht viel zu klein und unbedeutend wäre, als daß von meiner Entscheidung irgend etwas abhängen könnte. Ich glaubte vielmehr an mich. Ich erinnere mich sehr genau des Augenblicks, an dem ich am Arbeitstisch in der Dachkammer meines Elternhauses sitzend, laut zu mir 
selber sagte: „Ich muß es tun.“ Ich fand dabei bestätigt, daß Freiheit eine innere Bewußtseinstatsache ist; denn so sehr auch diese Entscheidung in meinem Wesen vorgebildet war, wußte ich, daß ich eine bewußte freie Entscheidung traf und daß sie mich noch stärker an den Weg band, den ich eingeschlagen hatte.

Mit der gesamten Redaktion und der Leipziger Parteileitung nahm ich sofort Partei für die Opposition. Bemühungen zu ihrex Sammlung setzten alsbald ein. Redaktion und Parteileitung kamen mit Karl Liebknecht zusammen, dessen Aufgeregtheit aber kaum Besprechungen praktischer Absichten gestattete. Gemeinsam war uns allen die Überzeugung, daß der Krieg nicht in sechs Wochen zu Ende sein werde, wie allgemein geglaubt wurde, und da $\beta$ er nicht mit einem leichten Siege Deutschlands enden werde. Im Osten war die russische Gefahr zunächst deutlich genug. Einige Monate nach Kriegsausbruch erhielt Frau Hanna Hertz einen aufschlußreichen warnenden Brief von ihrer Schwester aus London, daß die englische Kriegsanstrengung erst allmählich in Gang komme, aber schon immens sei und daß man dort von einem Siege der Alliierten nach vier Jahren Krieg rede. Ich verkehrte damals häufig in der Wohnung von Paul und Hanna Hertz, in der auch Eugen Prager ein Zimmer gemietet hatte.

Von Anfang an stand vor uns ein großes Problem. Wir fühlten uns als die erbitterten Feinde des kaiserlichen Systems und seines Militarismus. Sollten wir seinen Sieg oder seine Schwächung durch eine Niederlage wünschen? Von der Rechten der Partei her war in den voraufgegangenen Diskussionen aus Anlaß der Internationalen Kongresse gewarnt worden: Die Niederlage des Systems ist die Niederlage des deutschen Heeres, und die Niederlage des deutschen Heeres ist die Niederlage Deutschlands und des deutschen Volkes. Wir zogen uns vorsichtig auf eine Abschätzung des Für und Wider durch den Austromarxisten Gustav Eckstein ${ }^{49}$ zurück, der einen Ausgang ohne Sieger und Besiegte als am günstigsten für die Partei und die Zukunft des Sozialismus herausrechnete.

[...]

Auf der anderen Seite entwickelten ich und meine Freunde in der Frage der Kriegsziele eine große Empfindlichkeit für alles, was nach Verrückung von Grenzpfählen aussah. Wir waren während des ganzen Verlaufs des Krieges unbedingte Gegner jedes Annexionismus und die eigentlichen status quo-Politiker. Das tiefere Motiv für diese unsere Haltung lag darin, daß wir weiterhin den Gang der Geschichte bestimmt zu sehen glaubten durch Klassenauseinandersetzungen, nicht Völkerkämpfe, und da $\beta$ wir nicht wünschten, daß die Klassenauseinandersetzungen innerhalb der Nationalstaaten durch Grenzveränderungen und darauf beruhende nationalistische Erregungen gestört würden.

Zunächst kam für die Zeitung der sofortige Absturz der Auflage und für ihre Redakteure der Zwang, unter der Zensur ${ }^{50}$ arbeiten zu müssen. Das war etwas ganz anderes als zuvor und ging mir gegen den Strich. Ich schied als Volontär aus und

40 Gustav Eckstein (1875-1916), Journalist, Mitarbeiter des Vorwärts, Lehrer an der Parteihochschule Berlin, Redakteur der "Neuen Zeit".

50 Nach der Verkündung des Kriegszustandes wurde das gesamte öffentliche Leben von den Militärbefehlshabern (stellv. kommandierende Generale in den Armeekorpsbereichen) überwacht. Die Presse wurde unter Zensur gestellt, die von eigenen Presseabteilungen der stellv. Generalkommandos ausgeübt wurde. Vgl. Militär und Innenpolitik im Weltkrieg 1914-1918. Bearb. v. Wilhelm Deist, Düsseldorf 1970, T.1, S. XL f., und S. 63 ff. - Kurt Koszyk, Zwischen Kaiserreich und Diktatur. Die sozialdemokratische Presse von 1914 bis 1933, Heidelberg 1958, S. 36 f. 
konzentrierte mich auf eine längere Arbeit über die Geschichte Indiens unter besonderer Herausarbeitung der Verbrechen des englischen Kolonialismus und Imperialismus. Sie erschien in Fortsetzungen in der Leipziger Volkszeitung. ${ }^{51}$ Gegen Ende des Jahres 1914 lud mich Dr. Adolf Braun ${ }^{52}$ ein, zu ihm an die „Fränkische Tagespost" in Nürnberg zu kommen, um mich auf die Übernahme der Chefredaktion des Würzburger „Fränkischen Volksfreund" vorzubereiten.

Adolf Braun war ein Austromarxist und mit den führenden Austromarxisten in Wien versippt und verschwägert. Sein Bruder war Heinrich Braun, ${ }^{53}$ der die Generalstochter Lily Braun geheiratet hatte. Seine Schwester war die Frau von Victor Adler, ${ }^{54}$ dem Führer der österreichischen Sozialdemokratie. Er war ungeheuer belesen, aber kein eigentlicher Denker. Er hielt die „Fränkische Tagespost" ${ }^{455}$ auf dem Niveau einer selbständigen und intellektuell geleiteten Parteizeitung. Der Grundzug seines Wesens war seine absolute Hingabe an die Bewegung, der er diente. Sie kam auch in seiner spartanischen Lebensführung zum Ausdruck. Seine Bücher, die sich vor allem mit Gewerkschaftsproblemen befaßten, waren klar, durchsichtig und solide, aber nüchtern. Er war zuvor Redakteur des „Vorwärts" in Berlin gewesen, wurde aber aus Preußen ausgewiesen und durfte preußisches Gebiet nicht mehr betreten. Deshalb übernahm er die „Fränkische Tagespost". Er betätigte sich daneben als Talentsucher unter den jüngeren Intellektuellen in der Partei. So hatte er Paul Hertz in die "Leipziger Volkszeitung“ gebracht, und bei einem Besuche in Leipzig war er auf mich aufmerksam gemacht worden.

Ich nahm die Einladung an und fuhr zu ihm nach Nürnberg. Seine pädagogische Absicht war, mich zusehen zu lassen, wie er seine eigene Zeitung leitete und mir klar zu machen, was die eigentlichen Aufgaben eines Redakteurs sind, der eine Zeitung führt. Der Zweck der Übung war auch, der Bezirksleitung von Unterfranken die Zusicherung geben zu können, daß ich trotz meiner Jugend dem Posten in Würzburg gewachsen sein würde. Er fand sehr bald heraus, da $\beta$ ich das alles eigentlich von selber wußte und wie fundiert bei mir die journalistische Arbeit war. In diese Zeit an der „Fränkischen Tagespost" fiel der Lusitaniafall. ${ }^{56}$ Er ließ mich einen Leitartikel darüber diktieren, dem er große Anerkennung zollte. Weiter setzte er mich an die Aufgabe, über die großen Friedenskonferenzen der Vergangenheit zu schreiben, um die Lehre einzuhämmern, daß jedem Krieg schließlich eine Friedenskonferenz folgen

51 Indien und England, LVZ v. 4., 5., 8., 9., 11., 12. und 13. Januar 1915.

52 Adolf Braun (1862-1929) betrieb als Angehöriger des linken Flügels der SPD die Wiedervereinigung zwischen SPD und USPD. 1919-1928 MdR, 1920-1927 Mitglied des SPD-Parteivorstands.

53 Heinrich Braun (1854-1927), Mitgründer der „Neuen Zeit“, Gründer und Herausgeber sozialpolitischer Zeitschriften: „Archiv für soziale Gesetzgebung und Statistik“, „Sozialpolitisches Zentralblatt", „Annalen für soziale Politik und Gesetzgebung“ u.a. Verheiratet mit der sozialdemokratischen Schriftstellerin Lily Braun, geb. von Kretzschmann (1865-1916).

54 Victor Adler (1852-1918), Arzt, wurde 1881 Sozialdemokrat, seit 1889 (Hainfelder Parteitag) bis zu seinem Tod Führer der Sozialdemokratischen Partei Ósterreichs, 1918 Staatssekretär des Auswärtigen.

55 Die 1878 gegründete „Fränkische Tagespost“ war neben der „Münchener Post“ die bedeutendste Tageszeitung der SPD in Bayern. Adolf Braun war von 1902-1907 und 1912-1920 Chefredakteur.

56 Am 7. 5. 1915 hatte ein deutsches U-Boot das britische Passagierschiff „Lusitania“ torpediert. Unter den 1198 Toten befanden sich 139 Amerikaner, was zu großer Erregung in den USA und einem scharfen Notenwechsel zwischen Washington und Berlin führte. Der U-Bootkrieg wurde daraufhin vorübergehend eingeschränkt. 
müsse. Ferner schrieb ich über das Problem, ob Politik amoralisch sein dürfe. Ich hatte die umfangreiche Bibliothek der Zeitung zur Verfügung, in der ich fleißig herumstöberte. Ich habe dort eine ganze Menge gelesen, was ich bisher noch nicht kannte.

Mit den Parteisekretären Hans Vogel ${ }^{57}$ und Hans Dill, ${ }^{58}$ die im gleichen Hause ihre Büros hatten, kam ich in diesen Tagen in ein sehr freundschaftliches Verhältnis. Sie waren nicht „radikal“, aber die dauernde Fehde und die Eifersüchteleien in der Partei in Bayern zwischen München und Nürnberg brachten sie in die Nähe des Radikalismus. Daneben aber und nicht zuletzt gewann ich die Stadt Nürnberg lieb, mit ihren berühmten alten Häusern, die von großer bürgerlicher Vergangenheit sprachen, ihren Kirchen und der Burg. Das war etwas ganz anderes als die eintönige Farblosigkeit der Arbeitsstadt Leipzig.

Mit Adolf Braun verband mich bald eine enge Freundschaft. Auf meiner Seite beruhte sie auf der Bewunderung und dem Respekt vor seiner Integrität und seiner Hingabe an die Bewegung. Er behandelte mich beinahe wie einen Sohn mit voller Anerkennung für meine journalistischen Fähigkeiten. Dies enge Verhältnis ist später getrübt worden, als wir im Verlaufe der inneren Parteiauseinandersetzungen in verschiedener Richtung zogen, wurde aber im Jahre 1922 voll wieder aufgenommen.

Ich konnte früher nach Würzburg gehen, als ich angenommen hatte. Am Abend vor meiner Abreise nach Würzburg saß ich mit ihm in seinem Lieblingskaffeehaus zusammen. Bei dieser Gelegenheit kramte er aus der Tasche einen der kleinen Zettel, auf die er Gedanken für Artikel oder Reden oder über Probleme mit einem dicken Füllfederhalter niederzuschreiben pflegte. Er schrieb auf den Zettel und gab ihn mir dann schweigend über den Tisch hinweg. Er hatte geschrieben: „Nur die uneigennützige Arbeit für ein großes Ziel gibt wahre Befriedigung." Es war ein Zitat von Helmholtz. Er brachte nicht nur sein eigenes Wesen zum Ausdruck und das, was er von mir erwartete. Diesen Geist der Pflichterfüllung gegenüber einer frei gewählten Aufgabe hatte ich bereits in meinem Elternhaus kennengelernt. Ex kennzeichnet das Leben vieler Intellektueller, die sich wie Adolf Braun dem Dienst an der Arbeiterbewegung gewidmet hatten und den niedrigen Lebensstandard hinnahmen, den ihnen die Bewegung dafür gewährte.

Ich fuhr nach Würzburg und wurde von dem Geschäftsführer der Zeitung, Beilicke, dem Bezirkssekretär, dem Landtagsabgeordneten Endres ${ }^{59}$ und dem Vorsitzenden der Würzburger Parteiorganisation, Bauer, ${ }^{60}$ am Bahnhof in Empfang genommen. Sie führten mich sofort in ein hinter der Kirche Stift Haugk gelegenes kleines und düsteres Bierlokal, um mich in die Besonderheiten der Zeitung und der Partei und den Würzburger Stil im allgemeinen einzuführen. Die Zeitung wie die Würzburger Organisation waren innerhalb der Gesamtpartei nicht von hervorragender Bedeutung, und es ging dort viel gemütlicher zu als in Leipzig oder anderen sächsischen

57 Hans Vogel (1881-1945), Holzbildhauer, 1912-1918 MdL Bayern, 1919-1933 MdR, 1931 mit Otto Wels Vorsitzender der SPD, ab 1933 im Exilvorstand der SPD in Prag, Paris und London.

58 Hans Dill (1887-1973), Porzellanmaler, Parteisekretär, 1919-1932 MdL Bayern, 1930-1933 MdR, Emigration nach CSR, 1938 nach Kanada.

59 Fritz Endres (1877-1963), Kupferschmied, Arbcitersekretär, 1912-1918 und 1920-1933 MdL Bayern, 1919/20 bay. Justiz- bzw. Innenminister, 1919-1920 MdR.

60 Johann Bauer (1853-1916), Zigarrenmacher, 1906-1914. Mitglied des Würzburger Gemeindekollegiums. 
Industriestädten. Von allen den Lehren, die mir erteilt wurden, war die amüsanteste, daß ich mich nicht dazu verführen lassen solle, unserem großen Gegner in Würzburg, dem katholischen Priester Liborius Gerstenberger ${ }^{61}$ galante Beziehungen öffentlich vorzuwerfen; denn, so wurde mir gesagt, die anderen könnten sonst vielleicht einigen unserer Leute ähnliches nachsagen, wofür mir einige warnende Beispiele erzählt wurden. Ich sperrte Mund und Nase auf, aber die Warnung war eigentlich unnötig, da ich in meinem jugendlichen doktrinären Überschwang ohnehin das Prinzip, den politischen Kampf nicht mit persönlichen Angriffen zu vermischen, für eines der Grundgesetze hielt, die in der sozialdemokratischen Presse hochgehalten würden, in der „bürgerlichen“ aber nicht. In den nächsten Jahren habe ich dann anhand der immer schärfer werdenden inneren Parteiauseinandersetzungen gelernt, daß der löbliche Grundsatz auch in der sozialdemokratischen Presse nicht hochgehalten wurde, auch nicht bei Auseinandersetzungen von Parteigenossen mit Parteigenossen.

So war ich also in Würzburg als Chefredakteur des „Fränkischen Volksfreundes" $" 62$ in der Semmelstraße installiert. Chefredakteur hieß: ich hatte einen Lokalredakteur und einen Redakteur für bayerische Angelegenheiten. Der letztere wurde später eingezogen, so daß wir beiden verbleibenden Redakteure die Zeitung machten. [...]

Die Zeitung mußte so hergestellt werden, daß von zehn Uhr morgens an die Postzüge für das von Aschaffenburg bis Bamberg reichende Verbreitungsgebiet bedient werden konnten, die Würzburger Auflage erschien dann nach elf Uhr morgens. Nur zwei Setzmaschinen, die eine von älterem Typ, standen zur Verfügung. Der Hauptinhalt der Zeitung wurde am Nachmittag und Abend vor dem Erscheinungstage hergestellt; am Morgen des Erscheinens, und zwar redaktionell von fünf Uhr morgens an, entstanden die erste Seite als Hauptnachrichtenseite und eventuell der Leitartikel. Demnach dauerte die Redaktionsarbeit von fünf Uhr bis gegen elf Uhr morgens und dann wieder von vier Uhr nachmittags bis sechs oder sieben Uhr. Sobald ich um neun Uhr mit dem Umbruch fertig war, sah ich zu, wie in einer kleinen Handstereotypie von den Matern der beiden letzten Seiten die Walzen für die Rotationsmaschine gegossen wurden. Des Personalmangels wegen mußte der Metteur diese Arbeit verrichten. Mit einigen der Setzer freundete ich mich an und lernte von ihnen die Grundbegriffe ihrer Kunst. In Zusammenarbeit mit ihnen und dem Metteur konnte ich der Zeitung ein modernes Gesicht geben. Diese Erfahrungen sind mir später am "Vorwärts" in Berlin zugute gekommen, wo ich inoffiziell Chef vom Dienst war und ziemlich regelmäßig den Umbruch von Abendblatt und Morgenblatt leitete. In der "Leipziger Volkszeitung“ dagegen konnte ich keinen Gebrauch davon machen, dort wurde die traditionelle Form der Zeitung festgehalten und alles den Metteuren überlassen.

Gegen elf Uhr morgens ging ich von der Zeitung zum Café Hirschen und traf dort andere Würzburger Journalisten, vor allem den Chefredakteur vom „Generalanzeiger" Theo Kaufmann. ${ }^{63}$ Wir fanden aneinander Gefallen, wir verglichen unsere

61 Liborius Gerstenberger (1864-1925), Geistl. Rat, Verlagsdirektor und Hauptschriftleiter des „Fränkischen Volksblatts“, 1895-1919 MdL Bayern, 1895-1925 MdR (Zentrum/BVP).

62 Der „Fränkische Volksfreund - Sozialdemokratisches Organ für Unterfranken und den Reichstagswahlkreis Bamberg“" war 1908 gegründet worden, die Auflage betrug 1910 5000, 1914. 7000 Exemplare.

o3 Theodor Kaspar Kaufmann (1880-1955), ab 1906 Theater-Kritiker, 1910-1941 Chefredakteur des „Würzburger General-Anzeiger". 
Leitartikel und vor allem unsere Theaterkritiken, die wir beide schrieben, solange das Stadttheater noch in Betrieb war. Neben dem rein politischen Teil übernahm ich die Berichterstattung über wichtigere Stadtratssitzungen, denn ich konnte stenografieren und der Lokalredakteur nicht. [. . . . ${ }^{64}$

Ich schloß eine enge Freundschaft mit dem zweiten Vorsitzenden der Parteiorganisation, dem Buchhändler Felix Freudenberger.$^{65} \mathrm{Er}$ gehörte einer in Würzburg und Frankfurt wohnenden weitverzweigten jüdischen Familie an. Sein Bruder war Gymnasialprofessor in Würzburg, ein Vetter der Inhaber des größten Herrenkonfektionsgeschäftes in Würzburg. Felix Freudenberger war hochgebildet, seine Frau war die Tochter eines Rabbiners, er selber war Stadtrat in Würzburg. Ich besuchte ihn täglich in seiner Buchhandlung in der Augustinerstraße, wo wir unsere Ansichten und Meinungen über den Krieg und den Gang des Krieges, über die Haltung der Regierung und die Lage in der Partei austauschten. Mit Ausnahme von einigen Wochenenden, an denen ich nach Nürnberg fuhr, um die persönlichen Beziehungen zu Adolf Braun aufrecht zu erhalten, nahm ich regelmäßig an dem traditionellen Sonntagsnachmittagsspaziergang der Großfamilie Freudenberger teil. [ . . . $]^{66}$

Wenn der Geschäftsgang in der Buchhandlung Freudenberger keine Gespräche gestattete, saß ich in einer Ecke auf einem Stuhl und beobachtete die Kundschaft, was sie verlangte und was die Kunden sprachen. Neben meinem Verkehr im Café Hirschen war dies ein ausgezeichnetes Mittel, um Menschen kennenzulernen, noch viel besser als die sommerlichen Abendbesuche auf dem Brauhauskeller oder in den Weinhäusern "Stachel“ oder „Kette“. Die Buchhandlung setzte übrigens bei katholischen Landpfarrern in der Umgebung von Würzburg in großen Mengen die illustrierte Sittengeschichte von Eduard Fuchs ab.

[...]

\section{Opposition gegen die Parteileitung und Übertritt zur USPD}

Wir teilten beide die Ansichten der Parteilinken, was politisch natürlich bedeutete, da $\beta$ wir der Reichsregierung nicht über den Weg trauten und daß wir die offiziellen Berichte über die Kriegslage niemals für bare Münze nahmen. Für mich war das ohnehin selbstverständlich, weil ich die täglichen Zensuranweisungen des militärischen Zensors, eines Obersten, erhielt und weil bei den Gesprächen mit den Würzburger Journalisten beim Frühschoppen im Café Hirschen manches erzählt wurde. Je stärker sich der innere Kampf in der Sozialdemokratischen Partei und ihrer Reichstagsfraktion entwickelte, desto stärker geriet dieser Konflikt in den Mittelpunkt meiner Gespräche mit Freudenberger. Wir waren beide entschiedene Gegner der Bewilligung der Kriegskredite durch die sozialdemokratische Fraktion im Reichstage.

Was die Kriegszensur anbetrifft, so zog ich mir immer stärker den Unwillen des Zensors zu, je klarer es wurde, daß ich in der Zeitung die Opposition in der Sozialdemo-

64 Kürzung von rund 2 Seiten (Ms. S. 64-66), die Schilderungen Würzburgs und seiner Umgebung enthalten.

65 Felix Freudenberger (1874-1927), ab 1911 Mitglied des Würzburger Gemeindekollegiums, 1914 Magistratsrat, 1919-1924 4. Bürgermeister, 1919 MdL Bayern.

${ }_{06}$ Kürzung von etwa 11/2 Seiten (Ms. S. 67-68), auf denen Geyer von seiner damals entstehenden Vorliebe für science fiction Literatur erzählt. 
kratischen Partei unterstützte. Einem dreitägigen Verbot im Jahre 1915 folgten Vorladungen, Verwarnungen und Verbotsdrohungen. [. . . $]^{67}$

Die Partei in Würzburg hatte wenig Gesicht. In Abwesenheit der meisten Männer im Kriegsdienst bestand die Parteimitgliedschaft aus älteren Leuten und Frauen und nur wenigen unabkömmlichen Industriearbeitern. Abgesehen von politischen Informationsabenden nahm ich meine Tätigkeit aus der Leipziger Arbeiterjugend wieder auf, indem ich den Parteimitgliedern Bildungsvorträge hielt und ihnen dabei das Hintergrundmaterial zu den jeweiligen Kriegsnachrichten lieferte. Dadurch wie durch den Einfluß der Zeitung konnte ich jederzeit auf Mehrheiten für meine Ansichten rechnen; am Ende meiner Zeit mehr als zuvor. Es war wie überall: das Absinken von Ernährung und Lebenshaltung stärkte die innerparteiliche Opposition. Der Bezirkssekretär und der Ortssekretär, die sich um eine Nuance von mir und Freudenberger unterschieden, wußten, daß sie keine Aussicht hatten, sich gegen uns beide durchzusetzen. Es gab deshalb in Würzburg in der Partei keine wirklichen heftigen Auseinandersetzungen mit Kampfabstimmungen, solange ich noch in Würzburg war. Anders lagen die Dinge in Aschaffenburg und vor allem in Schweinfurt, wo den Kern der Parteiorganisation die Arbeiter der Kugellagerfabrik Fichtel \& Sachs bildeten. Das Verbreitungsgebiet der Zeitung als ganzes genommen war schließlich am Ende meiner Laufbahn in Würzburg in eine betonte innerparteiliche Kampfposition geraten - keineswegs von mir ungewollt.

Mein Vater und meine Leipziger Freunde hatten natürlich erwartet, daß ich die Zeitung im Sinne der Opposition führen würde, und selbstverständlich hatten sie damit recht. Es hätte einen Bruch in meiner Persönlichkeit und in meinen Überzeugungen bedeutet, wenn ich anders gehandelt hätte, aber bei allem hätte ich mich im Parteikonflikt nicht so stark in der Zeitung zu engagieren brauchen, wie ich es tat. In meinem jugendlichen Eifer und getrieben von meinem Selbstbewußtsein brachte ich es nicht fertig, auftauchende Fragen zu übergehen oder nur kurz darüber zu berichten, sondern ich stellte zu allem ausdrücklich meine Meinung fest, zum mindesten, als der Konflikt sich zuspitzte. Daß ich dabei die Zeitung von Kriegsbegeisterung und Siegesjubel fernhielt, teilte ich mit Adolf Braun und der „Fränkischen Tagespost" und anderen Zeitungen.

In meinen Anfängen in Würzburg schrieb ich zunächst in meiner freien Zeit allgemeinere Aufsätze für die „Leipziger Volkszeitung“ und die „Fränkische Tagespost". Ein Thema, das ich ausführlich behandelte, war die Behauptung, daß Englands Haltung auf den Handelsneid Deutschland gegenüber zurückzuführen sei. Ich zeigte unter Ausbreitung beträchtlichen statistischen Materials, daß die tatsächliche Entwicklung bis zum Kriegsausbruch njcht nach einem Konkurrenzverhältnis hin tendiert hatte, sondern eher zu einer klar erkennbaren Arbeitsteilung der beiden untereinander und auf den internationalen Märkten. Für die „Fränkische Tagespost" verfaßte ich, gestützt auf ein Buch von Professor Gustav Steffen, eine Abhandlung über die imperialistischen Tendenzen bei den Großmächten unter besonderer Berücksichtigung der Frühzeitigkeit und Intensität des englischen Imperialismus [...]

Aber diese Art von Arbeit trat völlig zurück, als der Parteikonflikt sich zuspitzte. Ich war mir bewußt, daß ich als Leiter einer Zeitung in diesem Konflikt eine wichtige

67 Kürzung von einer knappen Seite (Ms. S. 70-71), hauptsächlich Mitteilungen über das Privalleben des Würzburger Zensors. 
Position in der Hand hielt. Die Auflage war extrem niedrig und die Zeitung konnte nur noch von Anleihen beim Parteivorstand leben - aber sie trug meine Ansichten von Aschaffenburg bis Bamberg, und meine Anschauungen gingen konform mit denen der Opposition. Im Juni 1915 druckte ich aus der „Leipziger Volkszeitung“ das Pronunciamento von Haase ${ }^{68}$ Bernstein und Kautsky, „Das Gebot der Stunde “60 genannt, als Leitartikel im „Fränkischen Volksfreund" nach. Ergebnis: drei Tage Verbot. Am 21. Dezember verteidigte ich die Ablehnung der Kriegskredite im Reichstag durch eine von meinem Vater geführte Oppositionsgruppe. ${ }^{70}$ Am 1. Mai 1916 besprach ich ausführlich die Verhaftung Karl Liebknechts. ${ }^{71}$

In den Anfängen des Parteikonflikts stimmten meine Ansichten noch mit denen Adolf Brauns in Nürnberg überein. Aber dann begannen sie abzuweichen. Er hielt es für seine Pflicht, an der Erhaltung der Einheit der Partei zu arbeiten, und deshalb nahm er eine vermittelnde Position zwischen der Mehrheit und der Opposition ein. Ich dagegen steuerte mit wachsender Entschiedenheit den oppositionellen Kurs. Das nahm mich bald vollständig in Anspruch. Ich hielt Versammlungen nicht nur in Würzburg, sondern im gesamten Verbreitungsbezirk der Zeitung. Häufig war ich in Schweinfurt, weil ich wußte, daß dieser Industrieort für die innerparteiliche Entwicklung in Nordbayern von besonderer Bedeutung war. Dort, wie an allen Orten, wo ich Versammlungen abhielt, gewann ich persönliche Freunde und Vertraute, die

68 Hugo Haase (1863-1919), Rechtsanwalt, 1897-1906 und 1912-1919 MdR, 1911-1916 einer der beiden Parteivorsitzenden der SPD, 1912-1915 zugleich Vors. der Reichstagsfraktion, 1917 Mitgründer und Vorsitzender der USPD, Nov.-Dez. im Rat der Volksbeauftragten.

69 Der Aufruf „Das Gebot der Stunde“, am 19. Juli 1915 in der LVZ veröffentlicht, verurteilte in scharfer Form Annexionen und Eroberungen und appellierte an die SPD, eine Politik des raschen Friedens auf der "Grundlage freier Vereinbarung“ zu treiben: „Mit den schönsten Uberlieferungen der Sozialdemokratie steht die Zukunft unseres Volkes auf dem Spiel, seine Wohlfahrt und seine Freiheit. Hat unsere Partei nicht die Macht, die Entscheidungen zu treffen, so fällt doch uns die Aufgabe zu, als treibende Kraft die Politik in der Richtung vorwärtszudrängen, die wir als die richtige erkannt haben." Abgedr. u.a. bei Eugen Prager, Geschichte der U.S.P.D. Entstehung und Entwicklung der Unabhängigen Sozialdemokratischen Partei Deutschlands, Berlin 1921, S.72-74. Die Mehrheit von Partei- und Fraktionsvorstand distanzierte sich öffentlich von diesem Aufruf, die LVZ wurde vom 23. Juni bis 1. Juli 1915 verboten.

70 Entgegen dem Grundsatz, daß die Beschlüsse der Fraktion im Plenum des Reichstags geschlossen vertreten werden mußten, hatte am 21. Dezember 1915 erstmals eine Minderheit von 20 Abgeordneten der SPD im Plenum gegen die Kriegskredite gestimmt. Weitere $22 \mathrm{Ab}$ geordnete der Fraktionsminderheit hatten vor der Abstimmung den Saal verlassen. Verhandlungen des Reichstags, 21.12.1915, Sten. Ber., S. 507 f. - Wortlaut der Erklärung Friedrich Geyers im Namen von 20 Abgeordneten der SPD auch in: Dokumente und Materialien zur Geschichte der Deutschen Arbeiterbewegung, Reihe II, Bd. 1, Berlin (O) 1958, S. 263-264. S. a. Fraktionssitzungen der SPD am 20. und 21.12.1915, in: Die Reichstagsfraktion der deutschen Sozialdemokratie 1898 bis 1918, Düsseldorf 1966, T. 2, S. $101 \mathrm{ff}$. - Das von der Fraktionsmehrheit scharf verurteilte Verhalten der Minderheit führte zunächst zum Rücktritt Haases vom Fraktionsvorsitz und dann - anläßlich einer weiteren Bewilligung von Kriegskrediten durch die Mehrheit am 24. März 1916 - zur Spaltung der SPD-Reichstagsfraktion. Die 18 Abgeordneten bildeten die Sozialdemokratische Arbeitsgemeinschaft (SAG) im Reichstag. (Karl Liebknecht und Otto Rühle waren schon im Januar 1916 aus der SPD-Fraktion ausgeschieden.) Vgl. Die Reichstagsfraktion der deutschen Sozialdemokratie, T. 2, S. $166 \mathrm{ff}$.

71 Karl Liebknecht war wegen einer Friedensdemonstration am 1. Mai 1916 auf dem Potsdamer Platz in Berlin verhaftet worden und in erster Instanz zu zweieinhalb Jahren, im Berufungsverfahren vom Oberkriegsgericht am 23. 8.1916 zu vier Jahren einem Monat Zuchthaus und Aberkennung der bürgerlichen Ehrenrechte (Verlust des Reichstagsmandats) für 6 Jahre verurteilt worden. 
ebenso dachten wie ich. Darüber hinaus knüpfte ich Verbindungen an mit den Chefredakteuren unserer Zeitungen in Hof und Bayreuth. ${ }^{\mathbf{7 2}}$ Die persönliche Bekanntschaft führte schließlich zur Koordination der politischen Arbeit. Zu dritt hielten wir eine Beratung in Bamberg ab, bei der wir die innerparteiliche Lage in Nordbayern prüften und übereinkamen, unsere Zeitungen auf der gleichen Linie zu führen. In Aschaffenburg war der Sekretär des Gewerkschaftskartells August Karsten ${ }^{\mathbf{7 3}}$ politischer Berichterstatter für den „Fränkischen Volksfreund“ und zugleich der Agent für den Vertrieb der Zeitung. Unsere Ansichten stimmten überein, wir hielten uns gegenseitig durch häufige Briefe auf dem Laufenden.

Selbst zur Zeit der Bamberger Besprechung war das Ziel dieser Aktivität nicht Vorbereitung einer Parteispaltung, sondern Stärkung der innerparteilichen Opposition mit der Hoffnung, noch während des Krieges oder nach dem Kriege eine Parteimehrheit für die Opposition zu gewinnen. Der gemeinschaftliche Einfluß der drei Zeitungen, die Parteiversammlungen, die wir abhielten, und die Entschließungen für die Minderheit der Reichstagsfraktion, die in den Versammlungen angenommen wurden, waren schließlich nicht mehr zu übersehen. Die Landesleitung Bayern sah sich der Tatsache gegenüber, daß ganz Nordbayern ins oppositionelle Lager überging. ${ }^{\mathbf{7 4}}$

Im Sommer 1916 wurde von der Rechten der Partei der Gedanke eines Kriegsparteitages in die Debatte geworfen, der sofort abgehalten werden sollte. Es war klar, daß auf einem solchen Parteitag die Fraktionsmehrheit eine Parteitagsmehrheit erhalten würde und daß dies als Grundlage für disziplinäres Vorgehen in der Partei gegen die Opposition benutzt werden würde. Gegen diesen Gedanken polemisierte nicht nur die „Leipziger Volkszeitung“. Auch Adolf Braun in Nürnberg hatte seine Bedenken, weil er sofortige Spaltung auf einem solchen Parteitag befürchtete. Er regte an, daß ich mich im „Fränkischen Volksfreund“ ebenfalls gegen die Parteitagsidee wenden sollte, was er mir nicht zweimal zu sagen brauchte, da ich auch von Leipzig aus vor diesen Plänen gewarnt worden war. Die drei nordbayerischen Zeitungen nahmen Stellung gegen die Parteitagsidee.

Zur gleichen Zeit veranstaltete Adolf Braun gemeinsam mit dem früheren Mitredakteur der "Neuen Zeit", Emanuel Wurm, ${ }^{75}$ eine Einigungs- und Verständigungskonferenz in Nürnberg mit der Hoffnung, aus dem rechten Flügel der Opposition und dem linken der Parteimehrheit eine Fraktion zu bilden, die stark genug

72 Chefredakteur der "Oberfränkischen Volkszeitung - Organ für Jedermann aus dem Volke“ in Hof war Max Blumtritt (1877-1931). Chef der "Fränkischen Volkstribüne" in Bayreuth war der spätere Reichstagsabgeordnete Fritz Puchta (1883-1945).

73 August Karsten (1888- ), 1914-1917 Gemeindebevollmächtigter in Aschaffenburg, 1919 bis 1924 Bürgervorsteher in Peine, 1920-1933 MdR (USPD/SPD).

74 Bei der Parteispaltung im April 1917 gingen lediglich die SPD-Ortsvereine Aschaffenburg, Schweinfurt und die Würzburger Sektionen Heidingsfeld und Randersacker mehrheitlich zur USPD über. Der Wahlkreis Hof mit der "Oberfränkischen Volkszeitung“ schloß sich im Oktober 1917 der USPD an; im Verbreitungsgebiet der Bayreuther „Fränkischen Volkstribüne" gab es jedoch keine USPD-Organisationen. In ganz Nordbayern war das Parteiklima im wesentlichen von Adolf Braun und seiner gemäßigten Einigungspolitik bestimmt. Vgl. Guido F. Knopp, Einigungsdebatte und Einigungsaktion in SPD und USPD 1917-1920. Unter besonderer Berücksichtigung der "Zentralstelle für Einigung der Sozialdemokratie". Phil. Diss., Würzburg 1975.

75 Emanuel Wurm (1857-1920), Chemiker 1890-1907 und 1912-1920 MdR, seit 1917 USPD, 1902-1917 Redaktionsmitglied der „Neuen Zeit“. 1918/19 Staatssekretär im Kriegsernährungsamt. 
wäre, um sowohl die Linke als auch die Rechte an einer offenen Spaltung der Partei zu verhindern. Ich weigerte mich, an dieser Konferenz teilzunehmen. Sie fand nicht den Anklang, den Adolf Braun erhofft hatte. ${ }^{76} \mathrm{Ihr}$ Mißerfolg machte es nur noch klarer, daß die beiden Richtungen in der Partei gewillt waren, hartnäckig an ihrem Kurs festzuhalten, auf Biegen oder Brechen. Die weiteren Entwicklungen dieses Jahres, in dem der Einfluß der Opposition unter dem Druck des herannahenden Hungerwinters und der zunehmenden Kriegsmüdigkeit wuchs, machten Brauns Einigungsund Versöhnungsbemühungen noch hoffnungsloser.

Die nordbayerische Opposition, an deren Führung ich beteiligt war, stand etwa auf der Linie des Zentrums der späteren USPD. Ich persönlich, der ich in Partei- und Organisationstradition aufgewachsen war, hielt trotz meiner radikaleren Ansichten nicht viel von den kleineren noch radikaleren Gruppen und Richtungen, die damals hervortraten und die im ganzen als Vorläufer der kommunistischen Partei anzusehen sind. Versuche, die von einzelnen dieser Gruppen gemacht wurden, mich zu den ihren zu zählen, fanden keine Gegenliebe. Eines Tages besuchte mich Dr. Hermann Duncker $^{77}$ mit solchen Absichten. Ich legte ihm dar, daß die immer größer werdende Zersplitterung der Opposition sie nur schwächen könne, und ich verwies ihn auf die Erfolge der geschlossenen nordbayerischen Opposition. [. . .]

Immerhin, man kann nicht sagen, daß die Wogen des innerparteilichen Kampfes in Nordbayern bis dahin sehr hoch gegangen wären. Anders stand es in Frankfurt, wo die Opposition unter Führung des Sekretärs Robert Dißmann ${ }^{78}$ damals bereits begann, eigene Organisationen aufzuziehen und Versammlungen abzuhalten. Dißmann war ein besonderer Freund des Reichstagsabgeordneten Georg Ledebour, ${ }^{70}$ der wiederum ein Freund meines Vaters war. Dißmann lud mich ein, in Frankfurter Versammlungen zu sprechen, was ich auch wiederholt tat. Im rein Persönlichen hatte

76 Zu der Nürnberger Konferenz am 23. Juli 1916 hatten Adolf Braun, Martin Segitz und Erhard Auer im Auftrag bayerischer SPD-Landtagsabgeordneter etwa ein Dutzend nichtbayerischer Sozialdemokraten eingeladen. Emanuel Wurm galt aufgrund einer falschen Pressemeldung als Mit-Initiator der Konferenz, er nahm überhaupt nicht teil und distanzierte sich energisch von dem Unternehmen. (Vgl. Brief an A. Braun, abgedruckt in: Fränkische Tagespost v. 1. 8. 1916.) Uber den Kreis der Teilnehmer an der Nürnberger Konferenz ist wenig bekannt; das Konferenzkommuniqué war sehr allgemein formuliert: „Die freie Zusammenkunft von Parteigenossen verschiedener Richtung, die am Sonntag in Nürnberg stattfand, war eines Sinnes in der Notwendigkeit, den Streit in der Partei zu begrenzen ... Die versammelten Parteigenossen haben eine Reihe von Vorschlägen erwogen, deren Verwirklichung in der nächsten Zeit geplant ist ..." (Fränkische Tagespost v. 25.7.1916.) Die SAG-Fraktion reagierte auf die Einigungsbemühungen in Nürnberg mit einer sehr ablehnenden Erklärung. Vgl. Knopp, Einigungsdebatte und Einigungsaktion, S. 7 ff.

77 Hermann Duncker (1874-1960), 1893 Beitritt zur SPD, 1903 Redakteur der LVZ, 1911 an der Zentralschule der SPD, ab 1914 Mitglied der Gruppe Internationale, dann des Spartakusbundes, 1919 zusammen mit seiner Frau Käte Mitglied der Zentrale der KPD, 1923-1933 maßgeblich in der Schulungsarbeit der KPD tätig, 1933 verhaftet, 1936 Emigration, 1947 Rückkehr, 1948 Direktor der Bundeshochschule des FDGB in Bernau.

78 Robert Dißmann (1878-1926), 1905 Sekretär des Metallarbeiterverbands in Frankfurt, 1912 Bezirkssekretär der SPD, 1917 der USPD für Hessen-Nassau, 1919 Vorsitzender des Deutschen Metallarbeiter-Verbandes, 1920-1926 MdR.

78 Georg Ledebour (1850-1947), vom Liberalismus zur SPD, 1900-1918 und 1920-1924 MdR, 1917 Mitgründer der USPD, 1919 Beteiligung am Januaraufstand, nach der Wiedervereinigung von USPD und SPD 1922 führte L. die Rest-USPD weiter, trennte sich 1923 von ihr, gründete 1924 die Splitterpartei "Sozialistischer Bund" und ging 1931 zur SAPD, 1933 Emigration in die Schweiz. 
dies zur Folge, daß ich dort meine erste Frau kennenlernte. Auswärtige Redner wurden von zwei hübschen Mädchen betreut, die begeisterte Anhängerinnen der Opposition waren, Toni und Anna. Toni Sender ${ }^{80}$ war Direktionssekretärin in einem Frankfurter Großunternehmen, Anna Elbert Sekretärin an der Frankfurter Ortskrankenkasse. Ihr Vater, ein aus Würzburg gebürtiger Bildhauer, war damals Verwalter der Gartenstadt Riederwald. ${ }^{81}$ Er war ein prominenter Frankfurter Parteigenosse, der während der Revolutionstage vorübergehend das Frankfurter Polizeipräsidium im Auftrag der USPD übernahm. ${ }^{82}$ Ich wurde abwechselnd von beiden Mädchen betreut, und beide versprachen mir, mich in Würzburg zu besuchen. Anna kam zuerst, sie besuchte ihre katholischen Großeltern in Würzburg. Ich fuhr mit ihr nach Nürnberg, wo ich sie Adolf Braun vorstellte, der mir sozusagen seinen väterlichen Segen gab, obgleich wir bereits zu dieser Zeit mehrfach sachlich aneinandergeraten waren. Die Sache endete mit unserer Heirat im Juli 1917. Die beiden Mädchen waren in der Partei ziemlich bekannt, bei der Minderheit der Reichstagsfraktion führten sie den Scherznamen: Ledebours Nichten.

Aber dies band mich noch stärkex an die radikalere Entwicklung, welche die Dinge in Frankfurt nahmen, und es führte dazu, daß die Aufmerksamkeit stärker auf mich gelenkt wurde und daß ich eine Reihe von Verbindungen zu oppositionellen Reichstagsabgeordneten aufnahm. Ich hatte in Leipzig einige organisatorische Erfahrungen gesammelt. Die Ausdehnung des oppositionellen Einflusses im Verbreitungsgebiet des „Fränkischen Volksfreunds" hatte keine besonderen organisatorischen Probleme gezeitigt. In Frankfurt wurde mit allen organisatorischen Mitteln gekämpft. Robert Dißmann gab mir in unseren Unterhaltungen sozusagen Unterricht in allen Tricks der Menschenbehandlung in der Organisation und in allen Kunstgriffen, die man schlechthin als liöhere organisatorische Demagogie bezeichnen kann.

Die Differenz zwischen mir und Adolf Braun wurde markanter. Nachdem er erkannte, daß seine wiederholten väterlichen Warnungen von mir nicht beherzigt wurden und ich mich immer stärker exponierte, schlief der Verkehr zwischen uns allmählich ein. Bei einem meiner letzten Besuche bei ihm in Nürmberg traf ich in der Redaktion Dr. Adolf Müller, ${ }^{83}$ den Chefredakteur der "Münchener Post“. Ich machte aus meinen radikalen Anschauungen kein Hehl. Er dagegen vertrat mir gegenüber die Idee des evolutionären Weges zum Sozialismus: Wachsen, mehr und mehr das Vertrauen des Volkes gewinnen, größere Fraktionen in den Parlamenten, bis wir die

so Toni Sender (1888-1964), seit 1906 Mitglied der SPD und der Gewerkschaft, seit 1917 USPD, 1918 Redakteurin der Zeitung „Volksrecht", 1919-1924. Stadtverordnete in Frankfurt, 1920 bis 1933 MdR, 1933 Emigration über ČSR und Belgien nach New York, wo sie zuletzt den Internationalen Bund Freier Gewerkschaften bei den UN vertrat. Vgl. Toni Sender, The autobiography of a German rebel, New York 1939.

81 Die „Riederwald-Kolonie“ war keine Gartenstadt sondern eine 1911 errichtete, vom „Volks-, Bau- und Sparverein" getragene Arbeitersiedlung im Osten Frankfurts. - Hans Elbert (1864 bis 1928), Bildhauer, lebte seit 1890 in Frankfurt und war dort in der Gewerkschaftsbewegung und in der SPD bzw. USPD aktiv, 1901 Geschäftsführer der Riederwald-Kolonie, außerdem ehrenamtlicher Wohnungsinspektor der Stadt Frankfurt.

82 Frau Resi Ehlen, St. Petersburg (Florida), eine Tochter Elberts, teilte mit, daß ihr Vater ehrenamtlicher stellvertretender Polizeipräsident in den ersten Wochen nach der Revolution gewesen sei. Möglicherweise war Elbert Mitglied der Präsidial-Kommission, der 3 Vertreter der SPD und 2 Vertreter der USPD angehörten. Vgl. Erhard Lucas, Frankfurt unter der Herrschaft des Arbeiter- und Soldatenrats 1918/19, Frankfurt 1969, S. 65 f.

83 Adolf Müller (1865-1943), 1893-1918 Chefredakteur der Münchener Post, 1899-1918 MdL Bayern (SPD), 1919-1933 deutscher Gesandter in Bern. 
weitere Entwicklung in unserem Sinne praktisch beeinflussen könnten. Ich fragte ihn, was er sich vorstelle und was geschehen würde, wenn die anderen unsere Stimmzettel nicht so bewerten würden wie wir selber und eventuell zur Gewalt gegen sozialdemokratische Parlamentsmehrheiten greifen würden. Auch könnten wir Parlamentsmehrheiten erzielen, ohne damit gesellschaftliche Machtpositionen zu gewinnen, die auf Grund der gegebenen Gesellschaftsstruktur in der Hand der anderen bleiben und auch ohne Gewalt erfolgreich gegen unsere Stimmzettelmacht eingesetzt werden könnten. Er gab mir darauf zwei Antworten. Die eine: Wenn wir so weit sind, daß wir an Mehrheiten denken können, werden die anderen klüger geworden sein und es sich überlegen, Gewalt zu gebrauchen. Die andere war etwas metaphysischer: Wenn wir unter demokratischen Verhältnissen so stark geworden sein werden, daß wir regieren können, wird sich vorher die gesellschaftliche Struktur geändert haben. Es war mir klar, daß er von der Haltung der Parteimehrheit im Kriege eine Demokratisierung und die Einbeziehung der Partei in den Staat und das Ende jener autoritären Intoleranz erwartete, die sie bisher davon ausschloß. [...]

Ich nahm im September 1916 an der Reichskonferenz der Sozialdemokratischen Partei in Berlin teil, auf der die verschiedenen Richtungen zu Worte kamen. ${ }^{84}$ Als ich die Rede Friedrich Eberts ${ }^{85}$ und seine Polemik gegen den Reichstagsabgeordneten Gustav Hoch ${ }^{86}$ gehört hatte, der im Sinne Adolf Brauns sprach, war ich völlig überzeugt, daß er die sehr unbequem anwachsende Minderheit aus der Partei herausbringen wollte, und zwar mit allen Mitteln und um jeden Preis, ehe sie noch durch die steigende Kriegsmüdigkeit im Volke und unter dem Einfluß wachsender Ernährungsschwierigkeiten zur Mehrheit werden würde, was bei objektiver Prüfung aller Umstände nicht nur als möglich, sondern auch als wahrscheinlich erschien. Ich hatte bisher Zweifel gehabt, ob das Drängen einiger Abgeordneter der Fraktionsminderheit auf Gründung einer neuen Partei sinnvoll sei. Aber von diesem Zeitpunkt an war ich fest überzeugt, und zwar stärker als mein Vater, daß die Rechte die Parteispaltung erzwingen würde. Ich intensivierte deshalb meine Verbindung zu den Führern der Opposition in Berlin und im Reiche. In meinen Versammlungen beschuldigte ich die Rechte der Spaltungsabsichten, ohne indessen für die Gründung einer neuen Partei Propaganda zu machen.

Die Gegenwirkung von Nürnberg und München setzte danach ein. Mich berührte besonders ein Versuch, der meinen Einfluß auf die Schweinfurter Organisation brechen sollte. Es wurde eine Parteiversammlung arrangiert, in der Adolf Braun das Referat halten sollte. Ich war natürlich anwesend und setzte zunächst durch, daß ich ein Gegenreferat erhielt. Die Schlußabstimmung in dieser Versammlung bedeutete eine eklatante Niederlage für ihn. [. . .]

Die inneren Parteiauseinandersetzungen in Nordbayern begannen nun ziemlich erbittert zu werden. Trotz der Geschlossenheit Nordbayerns waren wir immer eine Minderheit in der bayerischen Gesamtorganisation. Wir wußten es und fanden es auf

84 Protokoll der Reichskonferenz der Sozialdemokratie Deutschlands vom 21., 22. und 23. September 1916. Hrsg. vom Vorstand der Sozialdemokratischen Partei Deutschlands. - Eine Polemik Eberts gegen Hoch ist im Protokoll nicht nachweisbar.

85 Friedrich Ebert (1871-1925), 1913 Vorsitzender der SPD, Nov. 1918 Vorsitzender des Rats der Volksbeauftragten (zusammen mit Hugo Haase), 1919-1925 Reichspräsident.

86 Gustav Hoch (1862-1942), 1894 Redakteur der „Volksstimme“ in Frankfurt/M., 1902-1919 Stadtverordneter in Hanau, 1898-1903 und 1907-1928 MdR, gehörte zum linken Flügel der SPD, 1942 nach Theresienstadt deportiert. 
einer bayerischen Parteikonferenz in Nürnberg ${ }^{87}$ bestätigt, auf der Erhard Auer ${ }^{88}$ den Kampf gegen uns führte, in einer persönlichen Form, wie ich sie bei den Auseinandersetzungen niemals angewandt hatte. Unter anderem zitierte er Sätze aus einigen Briefen von mir an August Karsten in Aschaffenburg. Ich warf Auer danach vor, daß diese Briefe in seinem Auftrage gestohlen worden seien. Er leugnete es gar nicht, und auf die Mehrheit der Delegierten machte es keinen Eindruck.

Im Winter 1916 auf 1917 war das Leben in Würzburg unter dem Einfluß der bis in den April anhaltenden bitteren Kälte erheblich härter geworden. Ich war inzwischen in eine andere Wohnung gezogen. Meine Wirtin hatte nicht genug Kohle, ich selbst konnte keine erhalten. Mein kleines Schlafzimmer glich im härtesten Winter einem Eiskeller. Schließlich nahm ich mit Zustimmung der Geschäftsleitung täglich nach Redaktionsschluß in meiner Aktentasche zwei Braunkohlenbriketts mit, wohl in Zeitungspapier gewickelt, mit denen ich dann einen kleinen Kachelofen in meinem Schlafzimmer anheizte. Der halbstündige Weg zwischen meiner Wohnung und der Zeitung, den ich morgens um vier Uhr dreißig zu Fuß antreten mußte, war in der bitteren Kälte, die man infolge unzureichender Ernährung besonders hart empfand, kein Vergnügen.

Die Dinge spitzten sich nach der Februarrevolution in Petersburg $1917 \mathrm{zu}$. Auf einer Tagung vom 6 . bis 8 . April erfolgte die Gründung der USPD in Gotha, ${ }^{89}$ die selbstverständlich unter dem Eindruck des russischen Geschehens stand. Nach der offenen Parteispaltung nahm der Kampf um die Organisation und die Zeitungen an Intensität zu. Ich hatte an der Gründungsversammlung der USPD nicht teilgenommen, ließ aber in der Organisation wie in der Zeitung keinen Zweifel, daß ich im Geiste

87 Die Landeskonferenz der bayerischen SPD, an der außer den Reichstags- und Landtagsabgeordneten alle wichtigen Funktionäre teilnahmen, tagte am 31. März und 1. April 1917. Ein auch von Geyer vertretener Antrag der nordbayerischen Opposition, der sich gegen die Haltung des Parteivorstands der Minderheit gegenüber richtete, wurde mit großer Mehrheit abgelehnt. In einer Resolution, in der ,alle Bestrebungen zur Errichtung von Sonderorganisationen" verurteilt wurden, sprach sich die Mehrheit der Delegierten für die Einheit und Geschlossenheit der Partei in Bayern aus. Vgl. Vorwärts v. 4. 4.1917; s. a. Knopp, Einigungsdebatte und Einigungsaktion, S. $26 \mathrm{f}$.

88 Erhard Auer (1874-1945), Angehöriger des rechten SPD-Flügels, 1907-1933 MdL Bayern, 1919-1920 MdR, 1918/19 bay. Innenminister, 1918-1933 Führer der bay. SPD.

80 Am 7. Januar 1917 waren die "Sozialdemokratische Arbeitsgemeinschaft" und die "Gruppe Internationale" erstmals zu einer gemeinsamen Konferenz in Berlin zusammengekommen, bei der die Politik des SPD-Parteivorstands verurteilt und über Fragen der Taktilk im Reichstag, Eigentumsrechte an Parteizeitungen und organisatorische Probleme der Opposition verhandelt wurde. Der Parteivorstand der SPD wertete am 18. Januar 1917 diese Konferenz als Bruch der Parteidisziplin, beschloß die organisatorische Trennung der Mehrheit von der Minderheit und forderte am 22. Januar die Anhänger der Opposition zum Austritt aus der SPD auf. Im März lud daraufhin der Vorstand der SAG zu der Konferenz in Gotha ein. Die Gegensätze zwischen den beiden Hauptrichtungen der Opposition, dem durch Haase, Dittmann, Ledebour repräsentierten Vorstand der Arbeitsgemeinschaft einerseits und der Gruppe Internationale andererseits, zogen sich, wie schon bei der Januarkonferenz, durch alle Diskussionen und Abstimmungen des Gründungsparteitags. Als Namen für die neue Partei standen zur Debatte „Opposition der Sozialdemokratischen Partei Deutschlands", „Sozialdemokratische Partei Deutschlands, Opposition", „Internationale Sozialdemokratische Partei Deutschlands" und der mit 77 gegen 42 Stimmen angenommene Name „Unabhängige Sozialdemokratische Partei Deutschlands". Vgl. Protokoll über die Verhandlungen des GründungsParteitags der U.S.P.D. vom 6. bis 8. April 1917 in Gotha. Mit Anhang: Bericht über die Gemeinsame Konferenz der Arbeitsgemeinschaft und der Spartakusgruppe vom 7. Januar 1917 in Berlin. Hrsg. von Emil Eichhorn, Berlin 1921. 
der USPD wirken wollte. Ich machte mir keine Illusionen darüber, daß ich die Würzburger Position behaupten könnte. Mein Freund Freudenberger, der in manchen Dingen erheblich radikaler dachte als ich, schreckte dennoch vor dem Gedanken zurück, die Würzburger Organisation im Kampfe in die USPD zu überführen. Das tat unserer Freundschaft keinen Abbruch; denn ich fühlte wohl, daß er die Imponderabilien der Situation und die Mentalität der Würzburger Bevölkerung im allgemeinen und das Trägheitsmoment besser einschätzte als ich. Er schlug mir vor, wir sollten vorsichtig lavieren unter Vermeidung einer Kampfposition gegen die USPD. Aber ich war entschlossen, über den Rubikon zu gehen, und jede Verhüllung oder das Verschweigen meiner wirklichen Anschauungen hätte mich in Konflikt mit mir selber gebracht. Die russische Revolution schien alle meine Anschauungen und Erwartungen zu bestätigen und feuerte meinen Drang nach Aktivität an. Ich sah voraus, daß ich die Position in Würzburg nicht für die USPD halten konnte, und vor allem hatte ich ein Verlangen nach einem breiteren Wirkungsfeld, mehr im Zentrum des Geschehens. Was die Zeitung anbetraf, so kannte ich ihre wirtschaftliche Lage und die Verschuldung des Verlages an den Parteivorstand sehr genau.

Ende April erschien denn auch Otto Braun ${ }^{90}$ als Vertreter des Parteivorstandes in Würzburg, um die Exekution vorzunehmen. Er gehörte damals wegen dieser Funktion zu den bestgehaßten Leuten bei der Opposition. Eine Sitzung von Verlag, Zeitungskommission ${ }^{91}$ und Organisationsleitung wurde veranstaltet. Vor der Sitzung hatte ich ein kurzes vertrauliches Gespräch mit Otto Braun, der mich fragte, ob ich auf meiner Haltung bestehen wolle, es würde keinerlei Schwierigkeiten geben, wenn ich die Anschauungen des linken Flügels der Mehrheitspartei vertreten würde. Ich sagte ihm, ich hätte meinen Entschluß gefaßt, ich verstünde die Lage durchaus, und ich würde ihm deshalb in der Sitzung keinerlei Schwierigkeiten machen. Das schien ihm neu zu sein und ihn angenehm zu überraschen. Tatsächlich hat der Vorfall kein Ressentiment in meine Beziehungen zu ihm gebracht. Wir schüttelten uns die Hände, und dann lief die Sitzung nüchtern ab. Im Einvernehmen mit dem Chefredakteur der Zeitung wurde dessen vierteljährliche Kündigung beschlossen mit der Maßgabe, daß er seine Tätigkeit sofort einstellen sollte.

Ich brach meine Zelte in Würzburg ab und ging nach Leipzig zurück. Ich wußte, daß die Redaktion der „Leipziger Volkszeitung“, die eine Art von Zentralorgan der USPD war, und die Leipziger Parteiorganisation mein nächstes Wirkungsfeld sein würden. Ich war fünfundzwanzigeinhalb Jahre alt, als ich Würzburg verließ.

80 Otto Braun (1872-1955), 1911 Hauptkassierer der SPD, 1920-1933 MdR, 1920-1933 mit kurzen Unterbrechungen preuß. Ministerpräsident.

91 Alle lokalen SPD-Zeitungen hatten als Kontrollorgan eine gewählte Pressekommission, die die Koordination der Arbeit der Redaktion mit der örtlichen Parteiorganisation gewährleisten sollte. Mit Hilfe der Pressekommission konnte ebenso Einfluß auf die Redakteure genommen werden wie umgekehrt die Redaktionen ïber dieses Instrument auch auf die Parteiarbeit einwirkten. 